\title{
Antigemination, assimilation, and the determination of identity
}

\author{
Eric Baković \\ University of California, San Diego \\ bakovic@ling.ucsd.edu
}

\begin{abstract}
Avoidance of adjacent consonants that are 'sufficiently identical' — that is, identical except for possible differences in a small subset of specific features - is argued to result from joint satisfaction of a constraint against geminates (identical adjacent consonants) and other active constraints that independently require assimilation with respect to those features ignored in the determination of identity. At the heart of the proposal is the crucial dependence of antigemination on independent assimilation processes, a prediction that is independently verified in case studies from English and Lithuanian. The factorial typology of constraints at the core of the proposal is demonstrated to closely fit a significant range of observed cases.
\end{abstract}

\section{Table of Contents}

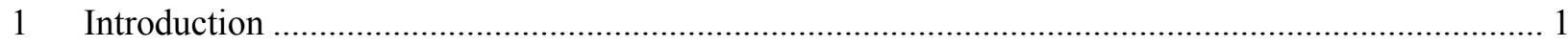

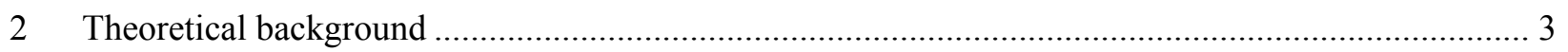

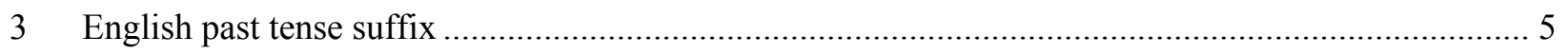

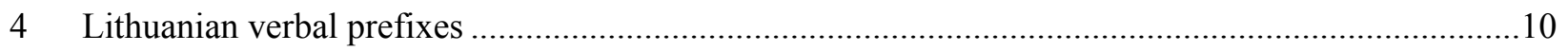

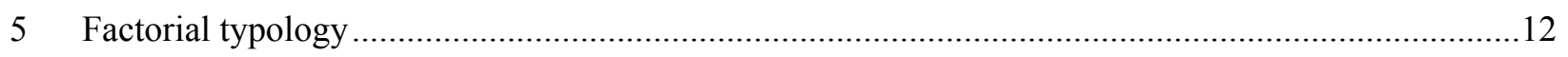

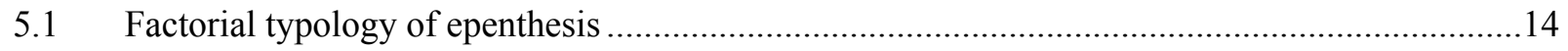

5.1.1 Insert a vowel only if flanking $\mathrm{Cs}$ are sufficiently identical ...........................................14

5.1.2 Insert a vowel only if flanking $\mathrm{Cs}$ are completely identical ..........................................15

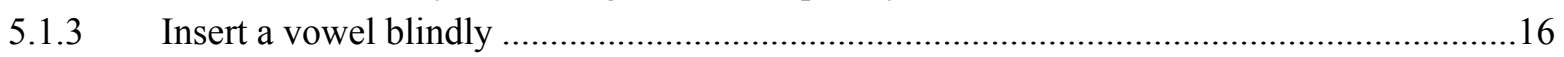

5.1.4 Insert a vowel unless flanking Cs are completely identical ...........................................17

5.1.5 Insert a vowel unless flanking Cs are sufficiently identical .............................................18

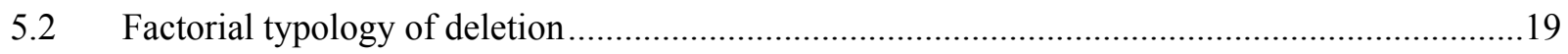

5.2.1 Delete a vowel unless flanking $\mathrm{Cs}$ are sufficiently identical..........................................20

5.2.2 Delete a vowel unless flanking $\mathrm{Cs}$ are completely identical ............................................22

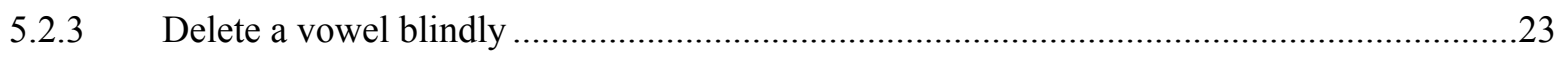

5.2.4 Delete a vowel only if flanking Cs are completely identical...........................................24

5.2.5 Delete a vowel only if flanking $\mathrm{Cs}$ are sufficiently identical ..........................................25

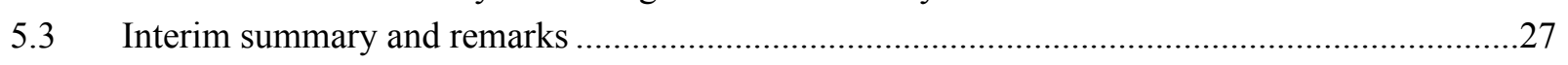

$5.4 \quad$ Triggering of dissimilation (and blocking of assimilation) .....................................................28

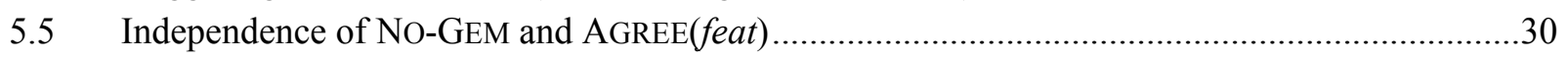

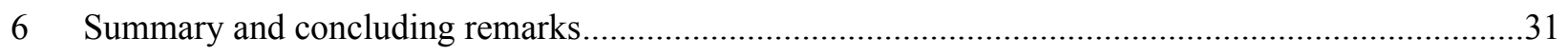

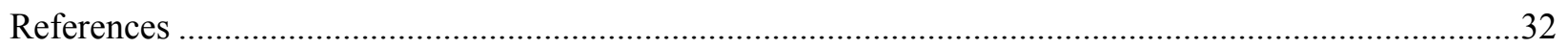




\section{Introduction}

This article ${ }^{*}$ is concerned with the avoidance, observed in a number of languages, of adjacent consonants that may or may not differ with respect to at most a small subset of specific features. In Lithuanian, for example (discussed in more detail in $\S 4$ ), the verbal prefixes /at/ and /ap/ surface as [at ${ }^{\mathrm{j}} \mathrm{i}$ ] and [ap ${ }^{\mathrm{j}} \mathrm{i}$ ], respectively, if the initial consonant of the stem is either identical to the prefix-final consonant or differs from it only in terms of voicing or palatalization (or both). Some key examples are given in (1).

(1) Sufficiently identical adjacent consonant avoidance in Lithuanian

\begin{tabular}{|c|c|c|}
\hline $\mathrm{a} t^{j} i-t^{j} \operatorname{eis}^{\mathrm{j} \mathrm{t}^{\mathrm{j}} \mathrm{i}} \quad$ 'to adjudicate' & $\mathrm{ap}^{j} i-p \mathrm{ut}_{\mathrm{i}}^{\mathrm{j}}$ & 'to grow rotten' \\
\hline at ${ }^{j} i-d$ uot $^{\mathrm{j}} \mathrm{i} \quad$ 'to give back, return' & $a p^{j} i-b^{j} \operatorname{err}^{j} t_{i}^{j}$ & 'to strew all over' \\
\hline$c f$. at $-k \mathrm{o}: \mathrm{p}^{\mathrm{j}} \mathrm{t}_{\mathrm{i}}^{\mathrm{j}} \quad$ 'to rise, climb up' & $c f$. a $p-k \mathrm{al}^{\mathrm{j}}$ & et ${ }^{\mathrm{j}} \mathrm{i}$ 'to slander' \\
\hline
\end{tabular}

McCarthy (1986) coined the term antigemination to refer to cases in which a regular vowel deletion process is blocked just in case the result would be a sequence of adjacent consonants that are 'sufficiently identical' in the sense described above. Following Yip (1988), I use this term to refer to sufficiently identical adjacent consonant avoidance in general, whether it is diagnosed by blocking of syncope (as in McCarthy's original set of examples) or by triggering of vowel epenthesis as in Lithuanian (and in other examples adduced by Yip). McCarthy's basic insight, which is applicable to both types of examples, is that the presence of a vowel is conditioned by the avoidance of adjacent identical consonants. This insight does not, however, satisfactorily explain why certain specific features — in Lithuanian, voicing and palatalization - may in some cases be ignored in the determination of adjacent consonant identity.

The question of primary concern in this article is this: short of stipulation, how can we determine whether two adjacent consonants are 'sufficiently identical' for the purposes of antigemination? The key to answering this question, I claim, lies in the otherwise expected behavior of adjacent consonants in the contexts of antigemination. In a set of contexts that includes those where antigemination is found in Lithuanian, for example, the first of two sufficiently different adjacent consonants assimilates to the second in terms of voicing and palatalization, as shown in (2)a. Thus, if a vowel were not epenthesized between prefix and stem in the examples in (1), the expected result of assimilation would be a sequence of adjacent identical consonants. An example of a counterfactual derivation of this sort is depicted in (2)b.

\footnotetext{
* I thank Jessica Barlow, Ed Keer, John McCarthy, David Perlmutter, Alan Prince, Sharon Rose, Colin Wilson, three anonymous reviewers and an associate editor of Phonology, and the audiences at WECOL 2004, SWOT 6, and UBC for constructive discussions of and feedback on the facts and issues addressed in this paper (not to mention important points of argument and style). These have all led to vast improvements in the paper, and any remaining shortcomings are my own responsibility.
} 
(2) Voicing/palatalization assimilation in Lithuanian
a. ad-gaut $\mathrm{j}_{\mathrm{i}}$ 'to get back'
ab-gaut $\mathrm{j}_{\mathrm{i}} \quad$ 'to deceive'
$\mathrm{a} t^{j}-p^{j}$ jaut ${ }^{j} \mathrm{i} \quad$ 'to cut off'
$\mathrm{a} p^{j}-t^{j} \mathrm{em}^{\mathrm{j}} \mathrm{d}^{\mathrm{j}} \mathrm{i}: \mathrm{t}^{\mathrm{j}} \mathrm{i}$ 'to obscure'
$\mathrm{a} d^{j}-b^{j} \mathrm{ek}^{\mathrm{j}} \mathrm{t}^{\mathrm{j}} \mathrm{i}$ 'to run up'
$\mathrm{a} b^{j}-g^{j} \mathrm{i}: \mathrm{d}^{\mathrm{j}} \mathrm{i} \mathrm{t}^{\mathrm{j}} \mathrm{i} \quad$ 'to heal (to some extent)'
b. $/ \mathrm{a} p-b^{j} \mathrm{er}^{\mathrm{j}} \mathrm{t}^{\mathrm{j}} \mathrm{i} / \rightarrow *\left[\mathrm{a} b^{j}-b^{j} \mathrm{er}^{\mathrm{j}} \mathrm{t}^{\mathrm{j}} \mathrm{i}\right] \quad$ 'to strew all over' (actual form: $\left[\mathrm{a} p^{j} i-b^{j} \mathrm{er}^{j} \mathrm{t}^{\mathrm{j}} \mathrm{i}\right]$ )

In other words, epenthesis of a vowel in this morphophonological context of Lithuanian is conditioned by two interacting demands: avoidance of adjacent identical consonants, and avoidance of adjacent consonants unassimilated for voicing and palatalization. Satisfaction of the latter demand - whether or not it is in fact only one demand or two separate ones - ordinarily results in regressive assimilation, except when the result of applying assimilation would jeopardize the former demand by creating adjacent identical consonants. In such a case, assimilation is blocked and vowel epenthesis is triggered instead.

This analysis makes a novel substantive claim: any feature ignored in the determination of identity for the purposes of antigemination must be one that can be independently justified by a separate pattern of avoidance of adjacent consonants that differ in terms of that feature. This article thus constitutes a response to the claim recently reasserted by Reiss (2003), following Odden (1988), that every relevant process may essentially stipulate which features can and which features cannot be ignored in the determination of segmental identity. The view I adopt here, in line with the recent growing literature on the calculation of segmental similarity (Berkley 2000, Côté 2004, Frisch et al. 2004, inter alia), is that what it means for two segments to be "basically the same type" (Langacker 1968:169-170) is "an embarrassment to current theory" (Harms 1978:50), an unfortunate state of affairs that can only be improved by exploring independent ways in which to predict the notions 'identical', 'sufficiently identical', 'similar', and so on.

The remainder of this article is an extended argument in favor of the analysis sketched above, paying special attention to its implications for phonological theory and typology. Some theoretical background is provided in $\S 2$, where I also make a case for the crucial use of output candidate comparison and constraint interaction in Optimality Theory (Prince \& Smolensky 1993/2004, henceforth OT). In §3 I discuss and analyze the morphophonemic alternation of the English past tense suffix, a relatively simple case of antigemination that ignores the independently assimilating feature of voicing. The slightly more complex case of Lithuanian is discussed and analyzed in $\S 4$. The factorial typology predicted by the core constraints involved in the proposal is reviewed in $§ 5$; patterns from a variety of languages corresponding to key slots in the predicted typology are also briefly discussed and analyzed there, demonstrating a satisfyingly close fit between predicted and attested patterns. A summary and conclusion in $\S 6$ wraps up the article. 


\section{Theoretical background}

The analysis of sufficiently identical antigemination sketched in $\S 1$ above requires relevant forms to follow an unusual derivational course. Given the Lithuanian input form /a $p-b^{j} \mathrm{er}^{\mathrm{j}} \mathrm{t}^{\mathrm{j}} \mathrm{i}$ ' to strew all over' (see (2)b above), the counterfactual result of applying assimilation, both voicing and palatalization in this case, must be considered in order to determine that epenthesis should have instead been triggered earlier to avoid adjacent identical consonants. In other words, the applicability of one process (epenthesis) is dependent on the potential result of another (assimilation). Compare this with the more usual type of situation found with the input form /ap-put $\mathrm{i}$ / 'to grow rotten' (see (1) above): only this input to epenthesis must be considered in order to determine that this rule should in fact be triggered in order to avoid adjacent identical consonants, rendering the correct output form [a $\left.p^{j} i-p \mathrm{ut}^{\mathrm{j}} \mathrm{i}\right]$.

This complex interaction makes perfect sense in the context of OT, for two key reasons. First, the derivation of an output from an input in OT is primarily accomplished via comparison of a set of fullyformed candidate outputs; in other words, consideration of false derivations (= nonoptimal candidates) is already a fundamental part of OT's derivational mechanism. Second, OT decouples phonological processes into structural descriptions defined by markedness constraints and structural changes governed by faithfulness constraints. This allows for situations, such as the present one, in which one structural description is implicated in more than one structural change.

The proposed analysis of sufficiently identical antigemination thus requires at least two markedness constraints on consonant sequences. One is a constraint I refer to here as AGREE(feat), penalizing adjacent consonants that do not share the same value of some feature feat. Crucially, AGREE(feat) can be satisfied either by assimilation or by rendering the relevant consonants nonadjacent, via the presence of an intervening vowel, the choice being made by the relative ranking of other constraints. This is incompatible with strict interpretations of recent work on the so-called 'too many solutions' problem (Steriade 2001a, b, Pater 2003, Bakovic \& Wilson 2004, among others); I share here the less strict view of de Lacy (2002, in press) and Baković (to appear), who provide more relevant examples and discussion. Otherwise, I do not commit myself to any other assumptions about AGREE(feat)-type constraints; see Pulleyblank (2002), Wilson (2003), McCarthy (2004), Archangeli \& Pulleyblank (to appear), and Baković (to appear) for recent reviews and critical examinations of various approaches to the analysis of assimilation within OT.

The other necessary markedness constraint is NO-GEM (Rose 2000), a constraint strictly penalizing adjacent completely identical consonants; in other words, geminates. NO-GEM here assumes the role of the segmental OCP in previous work on antigemination (except for Rose (2000), where both NO-GEM and the OCP are assumed to exist; see $\S 5$ for relevant discussion.) For the purposes of the analyses presented 
in this article, I find no reason to assume anything other than a representationally very inclusive definition of No-GEM that penalizes adjacent consonants that are specified with identical values for every feature (3)a, adjacent consonants that autosegmentally share some feature(s) and that are specified with identical values for all others (3)b, adjacent identical consonantal root nodes that autosegmentally share all features (3)c, and single consonantal melodies that are associated with adjacent timing slots (3)d. ${ }^{1}$

(3) Possible representations of e.g. [tt], all assumed to be penalized by NO-GEM
a. Two identical consonants
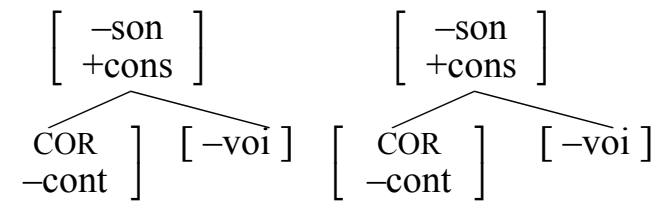
b. Two identical consonants, shared $[ \pm$ voi]

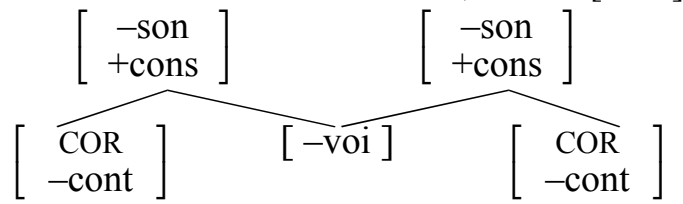

c. Two consonants, all features shared

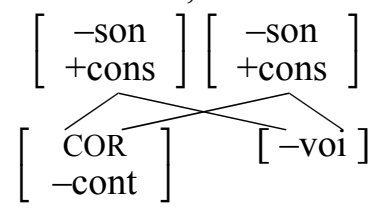

d. One consonant, two timing slots

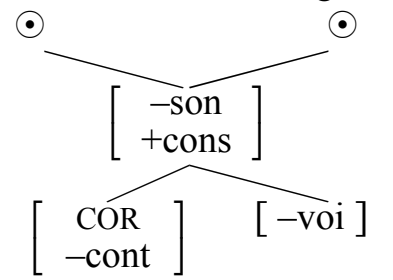

More to the point, which of these is or is not a legitimate representation of a geminate is not directly relevant to the concerns of this article. The best-established in the more recent literature on the topic are of course (3)c and (3)d (Perlmutter 1995); arguments specifically for the former are presented in Selkirk (1991) and for the latter in Hayes (1989). I simply assume that NO-GEM penalizes all basic ('true') and derived ('fake') geminates, regardless of how these are to be represented and whether they are to be represented differently. This assumption is in the basic spirit of Keer (1999:52ff) and Rose (2000:101ff).

Sufficiently identical antigemination is simply one among several ways to jointly satisfy AGREE(feat) and NO-GEM. In general, crucial violations of these two constraints can be collectively circumvented by forcing violation of some conflicting lower-ranked constraint(s) instead, as schematized in (4).

(4) General schema for sufficiently identical antigemination NO-GEM, AGREE(feat) $\gg$ LOWER

In this ranking schema, LOWER refers to the crucially lower-ranked constraint(s) defining candidates that, through violation of LOWER, escape violation of both NO-GEM and AGREE(feat). If LOWER is a constraint penalizing vowel epenthesis, for example, epenthesis will be triggered whenever the only other

\footnotetext{
${ }^{1}$ Whether the timing slots in (3)d are moras, syllables, subsyllabic constituents, etc. is not especially important here, hence the noncommittal symbol ' $\odot$ '.
} 
alternatives are possibly unassimilated but otherwise identical adjacent consonants — in other words, sufficiently identical adjacent consonants. Likewise, if LOWER is a constraint preferring vowel deletion, deletion will be blocked whenever the alternatives involve sufficiently identical adjacent consonants.

It follows from the schema in (4) that in any situation where AGREE(feat) and LOWER crucially conflict, candidates that violate LOWER are more harmonic than candidates that violate AGREE(feat). The prediction is thus that candidates violating $\operatorname{AGREE}(f e a t)$ are necessarily suboptimal even in derivations where violation of NO-GEM is not specifically at stake. This distinguishes features that can be ignored in the determination of identity from those that cannot in a principled way: for each feature feat that is ignored, AGREE(feat) must be independently active in the grammar. The proposal is thus further corroborated to the extent that $\operatorname{AgREE}(f e a t)$ can in fact be shown to be independently active in the grammar of each language with antigemination, and such is the case with the relevant examples discussed in this article. By crucially invoking independently active constraints in the grammar in this way, the proposed analysis of antigemination makes predictions and captures generalizations that an alternative analysis with an ad hoc constraint against sufficiently identical adjacent consonants in principle cannot.

Note that AGREE(feat) could in principle be any constraint that just so happens to penalize similarbut-not-identical adjacent consonants; the most obvious constraints for this role just happen to be the kinds of constraints that might otherwise enforce assimilation between adjacent consonants. The independent activity of such constraints, then, is likely to come from an independently demonstrable process of assimilation for each feature ignored by antigemination. When adjacent consonants are sufficiently identical and No-GEM is at stake, both NO-GEM and AGREE(feat) are satisfied by violating LowER instead; when adjacent consonants are sufficiently different, assimilation is not blocked and emerges as optimal. Such is the case with the two examples discussed in $\S \S 3-4$ below, beginning with English.

\section{English past tense suffix}

The English regular past tense suffix is a standard introductory textbook example of morphophonemic alternation (Hockett 1958, Langacker 1968, Fromkin 2000, among others). The research literature is also riddled with references to this example, with particular attention paid to it in such diverse works as Bloch (1947), Luelsdorff (1969), Hoard \& Sloat (1971), Basbøll (1972), Anderson (1973), Harms (1978), Kiparsky (1985), Borowsky (1986, 1987), Pinker \& Prince (1988), and Benus et al. (2004). The pattern of antigemination in this example is a model case for the current proposal: NO-GEM interacts crucially with another constraint the activity of which is independently motivated by an assimilation process apparent in the very same set of alternations. The resulting analysis illustrates in particularly clear terms a central re- 
sult of the current proposal; namely that in order to define in a principled way what it means for adjacent consonants to be sufficiently identical for the purposes of antigemination, NO-GEM must work in concert with other independently active constraints that are otherwise responsible for assimilation.

The past tense form of a verb in English is regularly formed by suffixation of one of three phonologically-conditioned alternants: a voiceless alternant [t], a voiced alternant [d], and a syllabic-and-voiced alternant [əd]. (Schwa [ə] is used as a cover symbol for whatever the exact quality of the vocalic element of this third alternant.) A phonologically identical suffix forms denominal adjectives (hooked [kt], horned [nd], talented [təd]); see Pinker \& Prince (1988:102). The distribution of each of these alternants is summarized descriptively in (5), glossing over flapping of / $t /$ and /d/ in some varieties of English.

(5) English past tense suffix alternations

\begin{tabular}{|c|c|c|c|c|}
\hline ALTERNANT & PHONOLOGICAL CONTEXT & EXAMPLES & & \\
\hline$[\mathrm{t}]$ & $\begin{array}{l}\text { following voiceless consonants } \\
\text { (other than } / \mathrm{t} / \text { ) }\end{array}$ & $\begin{array}{l}\text { tapped }[\mathrm{pt}] \\
\text { tacked }[\mathrm{kt}]\end{array}$ & $\begin{array}{l}\text { briefed }[\mathrm{ft}] \\
\text { ceased }[\mathrm{st}]\end{array}$ & \\
\hline$[\mathrm{d}]$ & $\begin{array}{l}\text { following vowels and voiced } \\
\text { consonants (other than } / \mathrm{d} / \text { ) }\end{array}$ & $\begin{array}{l}\text { tabbed [bd] } \\
\text { tagged [gd] }\end{array}$ & $\begin{array}{l}\text { lived }[\mathrm{vd}] \\
\text { seized }[\mathrm{zd}]\end{array}$ & $\begin{array}{l}\text { signed [nd] } \\
\text { sighed [ard] }\end{array}$ \\
\hline [əd] & following $/ \mathrm{t} /$ and $/ \mathrm{d} /$ & $\begin{array}{l}\text { seated [təd] } \\
\text { ceded [dəd] }\end{array}$ & & \\
\hline
\end{tabular}

Straightforward and uncontroversial arguments demonstrating that the underlying representation of the past tense suffix must be /d/ as opposed to /t/ or /əd/ are presented in Fromkin (2000:609ff), Pinker \& Prince (1988:101ff), and Benus et al. (2004). ${ }^{2}$ I accept these arguments and proceed under this assumption, but the basic point of the analysis is not substantively affected by this choice.

The distribution of the [əd] alternant is due to an epenthesis process, here attributed in part to NoGEM. In order to enforce epenthesis, NO-GEM must dominate the faithfulness constraint DEP-V penalizing a vowel in the output with no correspondent in the input. ${ }^{3}$

(6) Basic ranking responsible for epenthesis

$$
\text { NO-GEM } \gg \text { DEP-V }
$$

\footnotetext{
2 Pace Borowsky (1986, 1987), who assumes underlying /od/, and Kiparsky (1985), who appears to assume underlying /t/. Another possible analysis is a consonant unspecified for [ \pm voi]; see e.g. Davenport \& Hannahs (1998:173ff).

${ }^{3}$ Sequences violating NO-GEM occur "across certain morpheme boundaries" (Fromkin 2000:625): superrich, dissatisfied, unnecessary, vowellike, subbranch. A review suggests restricting No-GEM to word edges, reflecting "the stronger tendency to avoid geminates at word-edges than word-medially". Another possibility is to block all alternatives in these contexts such that No-GEM is forced to be violated; e.g., with a position-specific constraint penalizing epenthesis at the relevant morpheme boundaries.
} 
The distribution of the $[\mathrm{t}]$ alternant is due to a voicing assimilation process motivated by AGREE(voi), which penalizes tautosyllabic sequences of obstruents that disagree in $[ \pm$ voi]. Both the tautosyllabic and obstruent-sequence restrictions are necessary for this constraint in English; sequences of obstruents that disagree in [ \pm voi] across syllables are common (sucase [bk], backbone [kb], absolute [bs], baseball [sb]) as are tautosyllabic sequences of sonorants and [-voi] obstruents (apron [pr], application [pl], snow [sn], part [rt], pint [nt], fault [lt]). In order to enforce assimilation, AGREE(voi) must dominate the faithfulness constraint IDENT(voi) penalizing changes in [ \pm voi] from input to output. ${ }^{4}$

(7) Basic ranking responsible for voicing assimilation

$$
\text { AGREE(voi) } \gg \operatorname{IDENT}(\text { voi) }
$$

Of special interest here is that voicing assimilation does not apply betwee stem-final $/ \mathrm{t} /$ and the suffix /d/, and that epenthesis applies here instead. It would be possible to simply exclude / $/$ / from the set of voiceless consonants that trigger voicing assimilation, but this would not explain why exactly this consonant is excluded - the one consonant that differs from the past tense morpheme only in terms of the feature [ \pm voi]. Similarly, it would be possible to simply exclude [ \pm voi] from the set of features relevant to the epenthesis process responsible for the distribution of the syllabic alternant [əd], but this would not explain why exactly this feature is excluded - the one feature that, if allowed to assimilate as otherwise expected in $/ \mathrm{t}+\mathrm{d} /$, would yield a sequence of completely identical adjacent consonants.

Another way to look at the situation is as follows. Voicing assimilation unexpectedly fails to apply in the context $/ t+d /$, and epenthesis unexpectedly goes out of its way to apply in exactly this context. Precisely where one process loses ground, the other process gains it. These processes are clearly interacting with each other in some crucial way. Previous accounts appeal to extrinsic rule ordering: epenthesis precedes and bleeds voicing assimilation, accounting for the exceptionality of /t/ to the latter. ${ }^{5}$ The problem, of course, is that this still fails to explain the exceptionality of [ \pm voi] to epenthesis; the fact that $/ \mathrm{t} /$ and $/ \mathrm{d} /$ are 'sufficiently identical' for the purposes of epenthesis cannot be determined except by stipulation.

As discussed in $\S 2$, output candidate comparison and constraint interaction as defined in OT are perfectly suited to this kind of problem. Epenthesis applies to $/ \mathrm{t}+\mathrm{d} /$ because the crucial alternatives to the

\footnotetext{
${ }^{4}$ Note that it is the suffix rather than the stem-final consonant that alternates to satisfy AGREE(voi). Various ways to determine this choice are possible, none of which I commit to here; among them, root or stem/cyclic faithfulness (Beckman 1998, Benua 1997) or an appeal to the relative imperceptibility of voicing contrasts in the context C__ \# as opposed to V__ C (Steriade 1999).

${ }^{5}$ Harms (1978:46) and Pinker \& Prince (1988:106) go so far as to suggest that this ordering follows from phonology (epenthesis) preceding phonetics (voicing assimilation). Whether or not there is independent evidence for this modular division of labor in this case or otherwise, the constraints responsible for these processes are crucially intertwined in the analysis proposed here.
} 
epenthetic candidate [təd] are each ruled out by independently active constraints: No-GEM, penalizing the voice-assimilated candidate *[tt], and AGREE(voi), penalizing the faithful but unassimilated candidate *[td]. These two constraints thus jointly ensure the optimality of the epenthetic candidate [təd], which violates the lower-ranked faithfulness constraint DEP-V. This requires putting the rankings in (6) and (7) together and adding the further rankings AGREE(voi) $\gg$ DEP-V and DEP-V $\gg$ IDENT(voi).

(8) AGREE(voi) and No-GEM together ensure epenthesis ( $c f$. the schema in (4))

$$
\text { NO-GEM, AGREE(voi) } \gg \text { DEP-V } \gg \text { IDENT(voi) }
$$

The following tableau demonstrates how the ranking in (8) works with a stem ending in a [-voi] consonant other than $/ t /$. The assimilated candidate in (i) is preferred by undominated AGREE(voi), while the faithful candidate in (ii) is preferred by lower-ranked IDENT(voi). This justifies the ranking AGREE(voi) $\gg$ IDENT(voi). The epenthetic candidate in (iii) manages to satisfy AGREE(voi) as well as the optimal assimilated candidate does while performing better on IDENT(voi); the fact that the assimilated candidate is optimal justifies the ranking DEP-V $\gg$ IDENT(voi).

(9) English past tense after e.g. voiceless bilabial stop, tapped [pt]: voicing assimilation

\begin{tabular}{|c|c|c|c|c|}
\hline Input: /p+d/ & NO-GEM & AgREE(voi) & DEP-V & IDENT(voi) \\
\hline i. $\quad[\mathrm{pt}]$ & & & & $*$ \\
\hline ii. $\quad[\mathrm{pd}]$ & & $* !$ & & \\
\hline iii. $\quad$ [pəd] & & & $* !$ & \\
\hline
\end{tabular}

Note that no ranking of the constraints is necessary with a stem ending in a [+voi] consonant other than $/ \mathrm{d} /$, as shown in the next tableau. The relevant alternatives to the optimal faithful candidate in (i) the suboptimal devoiced candidate in (ii) and the suboptimal epenthetic candidate in (iii) — both fare worse on one or more of the constraints. The optimal faithful candidate in (i) satisfies them all.

(10) English past tense after e.g. voiced bilabial stop, tabbed [bd]: faithfulness

\begin{tabular}{|c|c|c|c|c|}
\hline Input: /b+d/ & NO-GEM & AGREE(voi) & DEP-V & IDENT(voi) \\
\hline i. $\quad[b d]$ & & & & \\
\hline ii. $\quad[\mathrm{bt}]$ & & $* !$ & & $*$ \\
\hline iii. $\quad$ [bəd] & & & $* !$ & \\
\hline
\end{tabular}

Things get more interesting with stems ending in coronal stops. The next tableau demonstrates how the ranking in (8) works with a stem ending in /d/. Comparing the optimal epenthetic candidate in (i) with the faithful candidate in (ii), the epenthetic candidate is preferred by undominated NO-GEM, while the 
faithful candidate is preferred by lower-ranked DEP-V. This justifies the ranking NO-GEM $\gg$ DEP-V. The suboptimal devoiced candidate in (iii) manages to satisfy NO-GEM as well as the optimal epenthetic candidate does while performing better on DEP-V; the fact that the epenthetic candidate is optimal justifies the ranking AGREE(voi) $\gg$ DEP-V. (Note that the comparison between these two candidates cannot justify IDENT(voi) $\gg$ DEP-V, because the opposite ranking was already established in (9) above.)

(11) English past tense after voiced coronal stop, ceded [dəd]: epenthesis

\begin{tabular}{|c|c|c|c|c|}
\hline Input: /d+d/ & NO-GEM & AGREE(voi) & DEP-V & IDENT(voi) \\
\hline i. $\quad[\mathrm{d} \partial \mathrm{d}]$ & & & $*$ & \\
\hline ii. $\quad[\mathrm{dd}]$ & $* !$ & & & \\
\hline iii. $\quad[\mathrm{dt}]$ & & $* !$ & & $*$ \\
\hline
\end{tabular}

The ranking AGREE(voi) $\gg$ DEP-V is also necessary to account for the fate of the input $/ \mathrm{t}+\mathrm{d} /$. The optimal epenthetic candidate [təd] fares worse than its competitors on DEP-V, but the faithful candidate *[td] and the assimilated candidate *[tt] violate higher-ranked AGREE(voi) and No-GEM, respectively.

(12) English past tense after voicelss coronal stop, seated [təd]: epenthesis

\begin{tabular}{|c|c|c|c|c|}
\hline Input: $/ \mathrm{t}+\mathrm{d} /$ & NO-GEM & AGREE(voi) & DEP-V & IDENT(voi) \\
\hline i. $\quad[$ təd $]$ & & & $*$ & \\
\hline ii. $\quad[\mathrm{td}]$ & & *! & & $*$ \\
\hline iii. $\quad[\mathrm{tt}]$ & $* !$ & & & \\
\hline
\end{tabular}

The key here is the way in which the dominant markedness constraints NO-GEM and AGREE(voi) work together to enforce epenthesis. The ranking of AGREE(voi) and DEP-V above IDENT(voi) establishes a preference for devoicing after stems ending in voiceless consonants, but in the case of $/ \mathrm{t}+\mathrm{d} /$ the result of devoicing would be *[tt], which is blocked by No-GEM. The ranking of NO-GEM and DEP-V above IDENT(voi) also (surprisingly) establishes a preference for devoicing in the case of $/ d+d /$; however, the result in this case would be *[dt], which is blocked by AGREE(voi). Epenthesis is the next best option in both cases, violating the higher-ranked of the two faithfulness constraints, DEP-V, but satisfying both of the even higher-ranked markedness constraints NO-GEM and AGREE(voi).

This analysis successfully explains why the conditions of potential applicability and those of actual application for each of the two processes differ in the way that they do. Voicing assimilation appears to be potentially applicable following all voiceless consonants because AGREE(voi) penalizes all sequences of voiced /d/ preceded by a voiceless consonant, but this process fails to actually apply after/t/ due to blocking by NO-GEM. Likewise, epenthesis appears to be potentially applicable only between consonants 
that have identical values for all features because NO-GEM only penalizes such sequences, but this process ignores the feature [ \pm voi] because of the equally high rank of AGREE(voi).

Space limitations unfortunately prohibit me from fully extending this analysis to cover the somewhat more complex alternations of the English plural suffix /z/, which triggers epenthesis not only with stems ending in /s/ or /z/ but also with stems ending in the remaining sibilants, $/ \int, 3, \widetilde{\mathrm{t}}, \widetilde{\mathrm{d}} /$. (Other suffixes that are phonologically identical to the plural include the $3^{\text {rd }}$ person singular present tense, the possessive, reduced has, is, and does, and a few others; see Pinker \& Prince (1988:102).) In order to explain the wider applicability of epenthesis in this case, some feature other than [ \pm voi] must be ignored; namely, the feature distinguishing $/ \mathrm{s}, \mathrm{z} /$ on the one hand from $/ \int, 3, \widehat{\mathrm{tf}}, \widehat{\mathrm{dz}} /$ on the other. This suggests that another $\operatorname{AGREE}(f e a t)$-type constraint is involved, this one penalizing (possibly also tautosyllabic) sequences of consonants like $/ 3^{+} \mathrm{z} /$ that differ in terms of the relevant feature. This result of the analysis has deeper consequences that are explored in detail in Baković (2005) and Baković \& Kilpatrick (2005).

\section{Lithuanian verbal prefixes}

As noted in $\S 1$, Lithuanian exhibits a pattern of antigemination that is identical to the English past tense (and plural) suffix alternations in relevant respects (Dambriunas et al. 1966, Mathiassen 1996, Ambrazas 1997). ${ }^{6}$ The verbal prefixes /at/ and /ap/ are realized as [at ${ }^{\mathrm{j}} \mathrm{i}$ and [ap ${ }^{\mathrm{j}} \mathrm{i}$, respectively, when prefixed to a stem beginning with a consonant that is sufficiently identical to the consonant of the prefix, where the features ignored in the determination of identity are voicing and palatalization.

(13) Lithuanian verbal prefixes: epenthesis

\begin{tabular}{|c|c|c|c|}
\hline $\mathrm{a} t^{j} i-t^{j} \operatorname{eis}^{\mathrm{j}} \mathrm{t}^{\mathrm{j}} \mathrm{i}$ & 'to adjudicate' & $\mathrm{a} p^{j} i-p \mathrm{ut}_{\mathrm{i}}^{\mathrm{j}}$ & 'to grow rotten' \\
\hline $\mathrm{a}^{j} i-d \mathrm{uot}^{\mathrm{j}} \mathrm{i}$ & 'to give back, return' & $a p^{j} i-b^{j} \operatorname{err}^{j} t^{j}{ }_{i}$ & 'to strew all over' \\
\hline $\mathrm{a} t^{j} i-d^{j} \mathrm{et}^{\mathrm{j}} \mathrm{i}$ & 'to delay, put off, postpone' & $\mathrm{a} p^{j} i-b^{j} \mathrm{ek}^{\mathrm{j}_{\mathrm{t}} \mathrm{j}_{\mathrm{i}}}$ & 'to run around' \\
\hline
\end{tabular}

The prediction made by the current proposal is that there must be independent voicing and palatalization assimilation processes in Lithuanian, given that these features are ignored by the epenthesis process in (13). And indeed there are: obstruents agree in voicing with a following obstruent, and all consonants agree in palatalization with a following consonant (Dambriunas et al. 1966:17, Kenstowicz 1972:9, Mathiassen 1996:25, Ambrazas 1997:44-45). The effects of both processes can be seen in the alternations of the same verbal prefixes, when the stem begins with a sufficiently different consonant.

\footnotetext{
${ }^{6}$ Many thanks to Sharon Rose for bringing these data to my attention. This pattern is also discussed in textbook form by Odden (2005:113-115), who does not include palatalization in his transcriptions and discussion (possibly for pedagogical reasons).
} 
(14) Lithuanian verbal prefixes: voicing and palatalization assimilation

a. Voiceless, nonpalatalized

\begin{tabular}{|c|c|c|c|}
\hline $\mathrm{at}-$ pra $\int^{\mathrm{j}} \mathrm{i}_{\mathrm{t}} \mathrm{t}_{\mathrm{i}}$ & 'to ask' & $\mathrm{ap}-\int \mathrm{auk}^{\mathrm{j}} \mathrm{t}_{\mathrm{i}}$ & 'to proclaim' \\
\hline $\mathrm{a} t-k \mathrm{o}: \mathrm{p}^{\mathrm{j}} \mathrm{t}_{\mathrm{i}}$ & 'to rise, climb up' & $\mathrm{a} p-k \mathrm{al}^{\mathrm{j}} \mathrm{b}^{\mathrm{j}} \mathrm{et}^{\mathrm{j}} \mathrm{i}$ & 'to slander' \\
\hline $\mathrm{at}-r \mathrm{as}^{\mathrm{j}} \mathrm{t}_{\mathrm{i}}$ & 'to find, discover' & $\mathrm{a} p-r a \int^{\mathrm{j}_{\mathrm{i}}: \mathrm{t}_{\mathrm{i}} \mathrm{j}_{\mathrm{i}}}$ & 'to describe' \\
\hline \multicolumn{4}{|c|}{ Voiced, nonpalatalized } \\
\hline $\mathrm{a} d-b \mathrm{uk}^{\mathrm{j}} \mathrm{t}_{\mathrm{i}}^{\mathrm{j}}$ & 'to become blunt' & $\mathrm{a} b-d \operatorname{ras}^{\mathrm{j}} \mathrm{k}^{\mathrm{j}} \mathrm{i}: \mathrm{t}^{\mathrm{j}} \mathrm{i}$ & 'to tear' \\
\hline ad-gaut $\mathrm{j}_{\mathrm{i}}$ & 'to get back' & $\mathrm{a} b$-gaut $\mathrm{j}_{\mathrm{i}}$ & 'to deceive' \\
\hline \multicolumn{4}{|c|}{ Voiceless, palatalized } \\
\hline $\mathrm{a} t^{j}-p^{j}$ jaut $^{\mathrm{j}_{\mathrm{i}}}$ & 'to cut off' & $\mathrm{a} p^{j}-t^{j} \mathrm{em}^{\mathrm{j}} \mathrm{d}^{\mathrm{j}} \mathrm{i}: \mathrm{t}_{\mathrm{i}}^{\mathrm{j}}$ & 'to obscure' \\
\hline & & $\mathrm{a} p^{j}-k^{j} \mathrm{el}^{\mathrm{j}} \mathrm{aut}{ }^{\mathrm{j}} \mathrm{i}$ & 'to travel through, around' \\
\hline
\end{tabular}

d. Voiced, palatalized

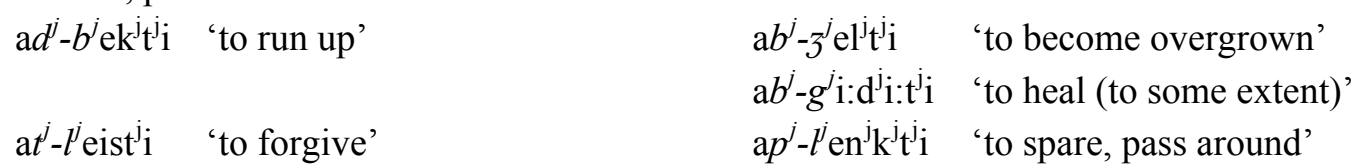

The analysis of this pattern is thus a straightforward adaptation of the ranking proposed for English, the only difference being that the constraints responsible for the assimilation of palatalization - call them AGREE(pal) and IDENT(pal) - must also be ranked in the same locations as AGREE(voi) and IDENT(voi), respectively. (AGREE(voi) must also be generalized so as to apply not only between tautosyllabic obstruents in Lithuanian; on the more general character of obstruent voicing neutralization in Lithuanian, see Steriade (1999).) The necessary ranking of the constraints in Lithuanian is given in (15).

(15) Antigemination ranking for Lithuanian AgReE(pal) No-GEM AgreE(voi)

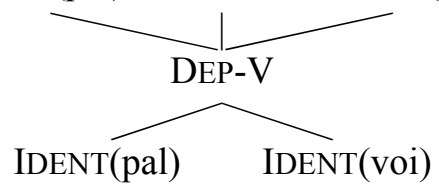

Compare Odden's (2005:115) discussion of the interaction between epenthesis and voicing assimilation: "Given just the voicing assimilation rule, you would expect forms [with adjacent identical consonants]. Lithuanian does not allow sequences of identical consonants, so to prevent such a result, an epenthetic vowel is inserted between homorganic obstruent stops" (emphasis added). In other words: even though the explicitly stated purpose of epenthesis is to prevent sequences of identical consonants, the proposed rule must still be formulated to apply between merely homorganic consonants — that is, to ignore voicing (and, in the full analysis, palatalization as well; see footnote 6).

The counterfactually expected forms that would result from assimilation alone are, of course, irrelevant to Odden's analysis: "Epenthesis eliminates the underlying cluster of obstruents, preventing [as- 
similation] from applying" (ibid). This bleeding interaction indeed correctly avoids a disallowed sequence of identical consonants, but this is an accidental by-product of the analysis; the purpose behind it is just in the mind of the analyst. The ranking in (15), by contrast, takes the teleological bull by the horns: NO-GEM only penalizes sequences of identical consonants, and it triggers epenthesis between sufficiently identical consonants only with the help of constraints that independently penalize unassimilated sequences.

\section{Factorial typology}

The focus of the preceding sections has been on a specific type of pattern: triggering of vowel epenthesis between sufficiently identical consonants, where the determination of identity ignores only features that independently assimilate in the same morphophonological context. This pattern follows, of course, from just one of several empirically distinguishable rankings of the kinds of constraints under consideration. In this section I review the entire factorial typology of relevant constraints and discuss the fit between the predicted typology and the typology of attested patterns, including not only patterns involving vowel insertion but also those involving vowel deletion; for example, the original type of antigemination pattern identified by McCarthy (1986), where syncope is blocked between sufficiently identical consonants. ${ }^{7}$

My task in this section is greatly facilitated by the fact that a substantial subset of the predicted typology was first addressed by Odden (1988) in his critique of McCarthy's (1986) OCP-based account; Rose (2000) and Reiss (2003) are two noteworthy examples of recent work that explicitly follow Odden's typological lead. Odden (1988:462) finds that syncope and epenthesis patterns corresponding to each of the six descriptive summaries in (16) are found among the world's languages. (Odden notes that "languages differ in what constitutes 'identical' segments” (ibid); I return to this very relevant point shortly.)

(16) Odden's typology of vowel deletion and epenthesis
a. Delete a vowel unless flanking Cs are identical.
b. Delete a vowel blindly.
c. Delete a vowel only if flanking Cs are identical.
d. Insert a vowel unless flanking Cs are identical.
e. Insert a vowel blindly.
f. Insert a vowel only if flanking Cs are identical.

The typology in (16) is a specific range of logically possible conditions on vowel deletion and insertion, beginning with those that satisfy the OCP in (16)a and (16)f, inverting the conditions by swapping 'unless' with 'only if' to render (16)c and (16)d, and simply removing the conditions to render (16)b and

\footnotetext{
${ }^{7}$ The results reported on in this section were double-checked with OTSoft (Hayes et al. 2003). The input files used with the program (and/or the output reports generated therefrom) are available from the author upon request.
} 
(16)e. The significance of the typology is that these latter four patterns are all attested: the ones in (16)b and (16)e, lacking a condition on deletion and insertion entirely, simply ignore the OCP; even more importantly, the patterns in (16)c and (16)d directly contradict the OCP because deletion and epenthesis appear to apply only if the result is an OCP violation. These latter two 'antiantigemination' patterns, as Odden appropriately calls them, constitute arguments-by-counterexample against McCarthy's account, even if the OCP is not "an absolute principle of Universal Grammar" (Odden 1988:451) but rather the somewhat weaker "parameter of Universal Grammar whose unmarked value is 'on"” (McCarthy 1986:256).

Rose (2000) proposes to resolve this problem for the OCP by splitting it into two separate and conflicting OT constraints, NO-GEM and the OCP. Rose assumes that adjacent identical consonants can only be represented as a single melody linked to two timing slots (3)d; this violates NO-GEM but not the OCP. Identical consonants across a vowel, on the other hand, violate the OCP but not NO-GEM. On Rose's account, then, satisfaction of NO-GEM requires antigemination (blocking syncope or triggering epenthesis only between identical consonants) and satisfaction of the OCP requires antiantigemination (blocking syncope or triggering epenthesis except between identical consonants). The remaining 'blind' patterns in the typology are due to other constraints simply requiring syncope or epenthesis, as under any account, with blind syncope sometimes violating NO-GEM and blind epenthesis sometimes violating the OCP.

In $\S \S 5.1-5.2$ below, I demonstrate how Odden's typology in (16) is described here without Rose's additional OCP constraint and without any specific representational assumptions about geminates. More importantly, I demonstrate how particular configurations of the core constraint types NO-GEM, $\operatorname{AGREE}(f e a t)$, and IDENT(feat) make specific predictions about whether any features - and if any, which ones - can be ignored in the determination of adjacent consonant identity; these predictions are supported in each case by brief discussions and analyses of relevant patterns from a variety of languages. After a brief interim summary in $\S 5.3$, I discuss the remainder of the predicted typology in $\S \S 5.5-5.4$.

In order to streamline the presentation to follow somewhat, I employ the abbreviations in (17).

(17) Abbreviations

a. $\forall \operatorname{AgREE}($ feat $) / \forall \operatorname{IDENT}($ feat $)=$ The set of all AGREE(feat)/IDENT(feat) constraints.

b. $\exists \operatorname{AGREE}($ feat $) / \exists \operatorname{IdENT}($ feat $)=$ A set of at least one AGREE(feat) / IDENT(feat) constraint.

c. $\Sigma \operatorname{AGREE}($ feat $) / \Sigma \operatorname{IDENT}($ feat $)=$ The complement set of $\exists \operatorname{AGREE}($ feat $) / \exists \operatorname{IDENT}($ feat $)$.

Within a single ranking, $\exists \operatorname{AGREE}(f e a t)$ and $\exists \operatorname{IDENT}($ feat $)$ refer to the same set of features, and from this it follows that $\Sigma \operatorname{AGREE}(f e a t)$ and $\Sigma \operatorname{IDENT}($ feat $)$ also refer to the same complement set of features. I will refer to the former set of features as $\exists$ feat and to the latter complement set as $\Sigma$ feat for convenience. 
It is important to emphasize that the only kind of AGREE(feat) constraint that is relevant here is the kind that penalizes featural disagreement in the relevant epenthesis/deletion context(s). For example, if an assimilation process only occurs between tautosyllabic obstruents (as English voicing assimilation seems to) but the result of not applying epenthesis (or the result of applying deletion) is never a tautosyllabic cluster, then this particular assimilation process does not impinge on NO-GEM and the AGREE(feat) constraint responsible for this assimilation process is irrelevant. The result of satisfying AGREE(feat) via violation of IDENT(feat) must also potentially result in total assimilation (that is, a geminate); if an assimilation process only occurs between consonants that are bound to remain distinct in terms of some other feature (e.g., nasal place assimilation only to following obstruents), then the particular AGREE(feat) constraint responsible for this assimilation process is again irrelevant. Accordingly, any AGREE(feat) constraint referred to in what follows is necessarily one that is not irrelevant in either of the senses just noted.

\subsection{Factorial typology of epenthesis}

I begin with the typology of epenthesis patterns in (16)d-f. Since I have been specifically concerned here with the distinction between identical and sufficiently identical adjacent consonants, the typological descriptions are expanded to explicitly indicate this distinction. The result is as given in (18).

(18) Revised typology of vowel epenthesis (cf. (16))

a. Insert a vowel only if flanking Cs are sufficiently identical.

b. Insert a vowel only if flanking Cs are completely identical.

c. Insert a vowel blindly.

d. Insert a vowel unless flanking Cs are completely identical.

e. Insert a vowel unless flanking Cs are sufficiently identical.

I discuss the rankings necessary to account for each of the patterns in (18) below, beginning with the now familiar one corresponding to the English and Lithuanian examples in $\S 3-4,(18)$ a.

\subsubsection{Insert a vowel only if flanking Cs are sufficiently identical}

In order to describe this pattern, NO-GEM and at least one AGREE(feat) constraint ( $\operatorname{AGREE}(f e a t)$ ) must be ranked above DEP-V. This accounts for the fact that epenthesis is employed in order to avoid sufficiently identical adjacent consonants, where 'sufficiently identical' means 'identical except that the set of features $\exists$ feat is ignored'. DEP-V must in turn outrank $\exists \operatorname{IDENT}(f e a t)$ in order to account for the fact that adjacent consonants that differ in their value(s) of $\exists$ feat only undergo epenthesis if they do not differ in their value of any other feature; otherwise, they undergo assimilation. In this way, any feature ignored in the determination of adjacent consonant identity is not an arbitrarily selected one; rather, it must be one that independently assimilates in the relevant set of contexts. 
All other AGREE(feat) constraints ( $\operatorname{AgREE}(f e a t))$ must be ranked below DEP-V, accounting for the fact that the complement set of features $\Sigma$ feat is not ignored. $\Sigma$ IDENT(feat) must outrank DEP-V in order to rule out dissimilation in terms of $\Sigma$ feat. (The possibility of dissimilation is addressed separately in $\S 5.4$ below.) $\Sigma$ IDENT(feat) thus outranks $\Sigma$ AGREE(feat) by transitivity, entailing that $\Sigma$ feat does not assimilate in the relevant set of contexts.

(19) Insert a vowel only if flanking Cs are sufficiently identical ((18)a)

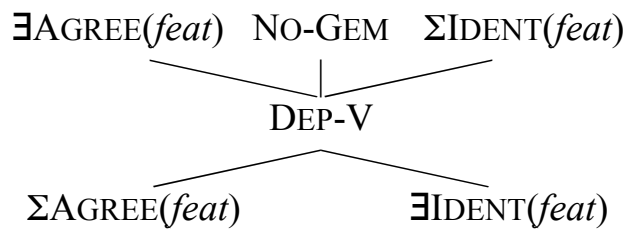

In the English past tense, $\exists$ feat is voicing; in the Lithuanian verbal prefixes, voicing and palatalization. Another example of this pattern is found in Modern Hebrew (Bolozky 1972, 1978, 1997, 2004, Odden 1988:463); the feature ignored by the optional epenthesis process is voicing (Bolozky 1978:49). When epenthesis does not apply between /d/ and /t/, voicing assimilation applies instead, resulting in a surface geminate as shown in (20)c-d. It is not clear whether or not voicing assimilation is optional in these cases; this process is otherwise dependent on speech rate and other factors (Bolozky 1978:16), as can be appreciated from the variation between sufficiently different consonants exhibited in (20)e.

(20) Vowel epenthesis in Modern Hebrew: only if flanking Cs differ at most in voicing
a. $/$ Savat $+t \mathrm{i} / \quad \rightarrow \quad$ [Saváteti] $\sim$ [Savátti] 'I was on strike'
b. $/ \mathrm{kifa} t+t \mathrm{a} / \rightarrow$ [kifáteta] $\sim[\mathrm{ki}$ átta] 'you decorated'
c. /ava $d+t \mathrm{i} / \quad \rightarrow \quad$ [avádeti] $\sim$ [avátti] 'I worked'
d. $/$ ora $d+t \mathrm{em} / \rightarrow$ [orádetem] $\sim$ [oráttem] 'you (pl.) removed'
e. $/$ kata $v+t i / \quad \rightarrow \quad[$ katáfti $] \sim[$ katávti $] \quad$ 'I wrote'

The optionality of voicing assimilation and epenthesis, and the restriction of the latter to $t$-initial suffixes, are matters that deserve further scrutiny and analysis. But it is clear that the situation is the same as it is in English and Lithuanian in relevant respects: all and only those features that independently assimilate in the relevant contexts are ignored in the determination of adjacent consonant identity. In the Modern Hebrew instantiation of the ranking in (19), $\exists$ feat is voicing and $\Sigma$ feat is the set of all other features.

\subsubsection{Insert a vowel only if flanking Cs are completely identical}

In order to describe this pattern, all AGREE(feat) constraints must be ranked below DEP-V. This accounts for the fact that sequences of nonidentical adjacent consonants are tolerated and do not trigger epenthesis. Because No-GEM is ranked above DEP-V, however, a vowel is epenthesized in order to avoid identical 
adjacent consonants. All IDENT(feat) constraints must also be ranked above DEP-V in order to rule out dissimilation as the way to avoid adjacent identical consonants (again, see $\S 5.4$ below). This ranking, shown in (21), therefore entails that no features assimilate in the relevant set of contexts. There is thus a necessary connection between the avoidance of only completely identical adjacent consonants, not merely sufficiently identical ones, and a lack of assimilation processes that might lead to such sequences.

(21) Insert a vowel only if flanking Cs are completely identical ((18)b)

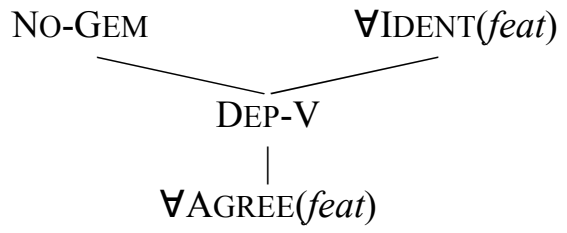

Within Tondano words (Sneddon 1975, Odden 1988:462), schwa epenthesis applies obligatorily between identical consonants and optionally otherwise. (Epenthesis between words in Tondano behaves differently, applying only if flanking Cs are not identical; see $§ 5.1 .4$ below.)

(22) Lexical schwa epenthesis in Tondano: only if flanking Cs are completely identical
a. $/$ kaPampit $+k \mathrm{u} / \rightarrow$ [kaPampitəku] $\sim[$ kaPampitku $] \quad$ 'my friend'
b. /lawas $+n \mathrm{a} / \quad \rightarrow \quad$ [lawasəna] [lawasna] 'his hand'
c. /kaPampit + ta/ $\rightarrow$ [kaPampitzta $/ *$ [ka?ampitta $] \quad$ 'our friend'
d. $/$ wu?uk $+k \mathrm{u} / \quad \rightarrow \quad[$ wu?ukəku] $/ *[$ wu?ukku] 'my hair'

While there are conditions on possible consonant clusters in Tondano (Sneddon 1975:21ff), there is no assimilation of any feature between consonants, in these contexts or elsewhere. This confirms the prediction made by the ranking in (21) that identity must be complete in order to trigger epenthesis because no features assimilate in the relevant contexts. The same conclusions apply to schwa epenthesis between identical consonants across a morpheme boundary in Lenakel (Lynch 1978:15ff, Odden 1988:462-463).

\subsubsection{Insert a vowel blindly}

In order to describe this pattern, all IDENT(feat) and AGREE(feat) constraints as well as No-GEM must be ranked above DEP-V. This accounts for the fact that a vowel is epenthesized in order to avoid all adjacent consonants, whether or not they are identical (and whether or not there might be assimilation). Alternatively, some other constraints against consonant clusters more generally (e.g., No-CODA, NO-COMPLEX) could be the motivation behind violation of DEP-V in this kind of case, in which case NO-GEM and the IDENT(feat) and AGREE(feat) constraints could in principle be ranked differently with respect to DEP-V. 
(23) Insert a vowel blindly $((18) c)$

$\forall$ AGREE(feat) NO-GEM $\forall \operatorname{IDENT}($ feat $)$

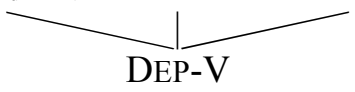

In Hua (Haiman 1980, Odden 1988:472-473), all consonant clusters except glottal stop + sonorant undergo epenthesis of a reduced (hence typographically superscripted) schwa, which adopts the quality of following full vowels across [r] and [r]. The examples in (24)c,d are constructed based on Odden's (1988:473) personal confirmation with John Haiman that insertion applies to these forms. (Note that assimilation of the reduced schwa is expected to apply only across the second $[\mathrm{r}]$ in (24)d.)

(24) Reduced schwa epenthesis in Hua: regardless of identity
a. /dtúl $\rightarrow\left[d^{2} t^{\prime} \mathbf{u}\right]$ 'lowlands softwood tree'
b. /kvrgíia/ $\rightarrow\left[k^{2} v^{2} r^{2} g i\right.$ ia $]$
'Job's tears'
c. Ifzzepzzefu/ $\rightarrow\left[f^{\partial} z^{\partial} z \mathrm{e} p^{\partial} z^{\partial} z \mathrm{efu}\right]$
'notch, striate'
d. /krrupai/ $\rightarrow \quad\left[k^{2} r^{u}\right.$ rupai $]$
'crash down'

In this case there is of course no question as to whether or not assimilation for any features is independently expected, because vowel epenthesis happens across the board.

\subsubsection{Insert a vowel unless flanking Cs are completely identical}

In order to describe this pattern, NO-GEM must be ranked below DEP-V. This accounts for the fact that no vowel is epenthesized in order to avoid adjacent identical consonants. DEP-V must in turn be ranked below all AGREE(feat) and IDENT(feat) constraints so that whenever consonants disagree in terms of any feature they do not assimilate but a vowel is epenthesized instead.

(25) Insert a vowel unless flanking Cs are completely identical ((18)d)

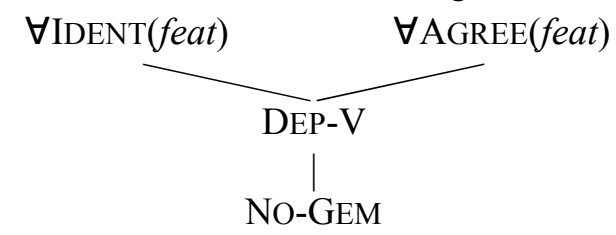

Between Tondano words (Sneddon 1975, Odden 1988:459), epenthesis optionally applies only between nonidentical consonants; adjacent identical consonants are realized faithfully.

(26) Postlexical schwa epenthesis in Tondano: unless flanking Cs are completely identical
a. /susur \# nədo/
$\rightarrow \quad$ [susurnədo] $\sim$ [susurənədo]
'every day'
b. /loit \# rintək/
$\rightarrow \quad[$ loitrintək $] \sim[$ loitərintək]
'small change'
c. /yaran \# ni \# tuama/ $\rightarrow$ [yarannituama] / *[yaranənituama]
'the man's name'
d. /mapuru $t$ \# tali/
$\rightarrow \quad[$ mapuruttali $] / *[$ mapurutatali $]$
'is picking up the rope' 
Again, there is no question here as to whether or not there is assimilation in the relevant contexts since epenthesis always applies unless flanking consonants are already identical.

\subsubsection{Insert a vowel unless flanking Cs are sufficiently identical}

In order to describe this final pattern, a ranking very similar to the one just discussed is necessary. NoGEM must again be ranked below DEP-V and many, though crucially not all, AGREE(feat) and IDENT(feat) constraints. Because complete identity is not necessary for epenthesis to be blocked, either the $\operatorname{AGREE}($ feat $)$ or the IDENT(feat) constraints referring to the set of features ignored in the determination of identity must be ranked with NO-GEM below DEP-V. The two possible rankings are shown in (27).

(27) Insert a vowel unless flanking Cs are sufficiently identical ((18)e)

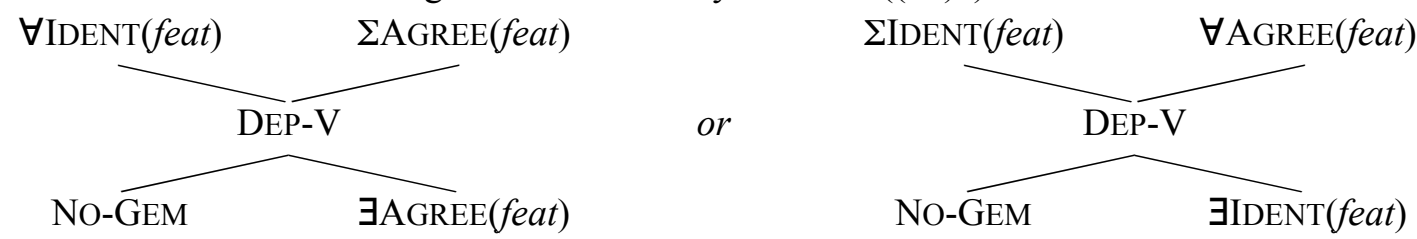

In the ranking on the left, epenthesis does not occur between sufficiently identical adjacent consonants because DEP-V dominates $\exists \operatorname{AGREE}(f e a t)$, where $\exists$ feat is the set of features ignored in the determination of identity. This means that there is also no assimilation in terms of $\exists$ feat, because the corresponding IDENT(feat) constraints are undominated. ${ }^{8}$ In the ranking on the right, on the other hand, epenthesis between sufficiently identical adjacent consonants is avoided because assimilation occurs in this case instead — creating geminates — due to the subranking $\forall \operatorname{AGREE}(f e a t) \gg \operatorname{DEP}-\mathrm{V} \gg \exists \operatorname{IDENT}($ feat $)$.

In Yir Yoront (Alpher 1973, 1991, Odden 1988:459), schwa epenthesis applies obligatorily between heterorganic consonants and optionally between homorganic consonants. Note that in the following transcriptions, /t $, \mathrm{n}, 1 /$ represent laminal (more specifically, lamino-dental) consonants which contrast with apical (alveolar and retroflex) consonants with the same manner of articulation; clusters of consonants differing in any of these three subcoronal places of articulation count as heterorganic.

(28) Schwa epenthesis in Yir Yoront: unless flanking Cs are homorganic
a. $/ \mathrm{lul} t+t \mathrm{i} \mathrm{il} /$
$\rightarrow \quad\left[\operatorname{lult} t t_{a} \mathrm{il}\right] / *[\operatorname{lulttt} \mathrm{il}]$
'cave'
b. $/$ kow + ll
$\rightarrow \quad[\mathrm{kowal}] / *[\mathrm{kowl}]$
'nasal'
c. $/$ warm $+l_{a}+n_{a} / \quad \rightarrow \quad[$ warmol $\partial n] \sim[$ warmoln $n]$ 'died'
d. $/ \mathrm{t} u t+t$ innuw/ $\rightarrow$ [tatztinnuw $] \sim[$ t $\mathrm{u} t$ tinnuw $]$ 'went and stood'

\footnotetext{
${ }^{8}$ Technically, ЭIDENT(feat) needn't be ranked above DEP-V as suggested by this ranking, but $\operatorname{IDENT}($ feat $)$ must at least dominate both No-GEM and $\exists \operatorname{AgREE}(f e a t)$ and so the point made in the text that it is undominated is unaffected.
} 
Unfortunately, whether or not any place of articulation assimilation is otherwise expected in these contexts is not known from available examples, thus it is unclear whether Yir Yoront instantiates the ranking on the left or the ranking on the right in (27). Alpher (1991:17) notes that some speakers "routinely assimilate" laminal stops and nasals $/ \mathrm{t}, \mathrm{n} /$ to preceding apical sonorants $/ \mathrm{l}, \mathrm{n}, \mathrm{l}, \mathrm{q} /$ "when the sequence occurs across a boundary between two members of a compound or a close-knit phrase", but none of the examples cited in this (short) section indicate whether epenthesis also occurs in these contexts.

The distinction between the two rankings in (27) represents an interesting typological result of the current proposal: triggering of epenthesis only by sufficiently identical adjacent consonants (antigemination) crucially depends on assimilation, while blocking of epenthesis only by sufficiently identical adjacent consonants (antiantigemination) is expected regardless of whether or not the features ignored in the determination of identity independently assimilate. Any features ignored in the case of antigemination are ignored precisely because their independently expected assimilation would lead to the creation of adjacent identical consonants - a fatal violation of NO-GEM, which is undominated. In the case of antiantigemination, NO-GEM is crucially dominated by DEP-V; some features are ignored in the determination of identity simply because the relevant AGREE(feat) constraints are those that do not trigger epenthesis, due either to $\exists \operatorname{IDENT}($ feat $) \gg \operatorname{DEP}-\mathrm{V} \gg \exists \operatorname{AGREE}($ feat $)$ (the ranking on the left in (27), no assimilation) or to $\exists \operatorname{AGREE}(f e a t) \gg \mathrm{DEP}-\mathrm{V} \gg$ $\operatorname{IDENT}(f e a t)$ (the ranking on the right, with assimilation). Antigemination is thus crucially dependent on assimilation in a way that antiantigemination is not. A parallel situation arises with respect to vowel deletion, as I discuss in $§ 5.2 .5$ further below.

\subsection{Factorial typology of deletion}

The typology of deletion also needs to be expanded to explicitly indicate the distinction between identical and sufficiently identical consonants; the result is as given in (29). Note that since it is deletion we are concerned with now and not epenthesis, DEP-V will be replaced in all rankings by a markedness constraint NO- $[V]$ - which penalizes whatever vowel needs to be deleted — ranked above MAX-V, the faithfulness constraint penalizing vowel deletion. MAX-V will itself never be crucially ranked with respect to any constraint other than No- $[V]$, and so I will ignore MAX-V in the discussion of each ranking.

(29) Revised typology of vowel deletion

a. Delete a vowel unless flanking Cs are sufficiently identical.

b. Delete a vowel unless flanking Cs are completely identical.

c. Delete a vowel blindly.

d. Delete a vowel only if flanking Cs are completely identical.

e. Delete a vowel only if flanking Cs are sufficiently identical. 


\subsubsection{Delete a vowel unless flanking Cs are sufficiently identical}

In order to describe this pattern, NO-GEM and at least one AGREE(feat) constraint ( $\operatorname{AGREE}(f e a t)$ ) must be ranked above No- $[\mathrm{V}]$. This accounts for the fact that deletion is blocked in order to avoid sufficiently identical adjacent consonants, where 'sufficiently identical' means 'identical except that the set of features $\exists$ feat is ignored'. NO- $[\mathrm{V}]$ must in turn outrank $\exists \operatorname{IDENT}(f e a t)$ in order to account for the fact that consonants flanking a relevant vowel that differ in their value(s) of $\exists$ feat only block deletion of the vowel if they do not differ in their value of any other feature; otherwise, the vowel deletes and the consonants undergo assimilation. Again, any feature ignored in the determination of identity is thus not an arbitrarily selected one; it must instead be one that independently assimilates in the relevant set of contexts.

All other AGREE(feat) constraints ( $\operatorname{AGREE}(f e a t))$ must be ranked below No- $[V]$, accounting for the fact that the complement set of features $\Sigma$ feat is not ignored. $\Sigma$ IDENT(feat) must outrank NO-[ $V]$ in order to rule out dissimilation in terms of $\Sigma$ feat between identical consonants (see §5.4). $\Sigma$ IDENT(feat) thus outranks $\Sigma$ AGREE(feat) by transitivity, entailing that $\Sigma$ feat does not assimilate in the relevant set of contexts.

(30) Delete a vowel unless flanking Cs are sufficiently identical ((29)a)

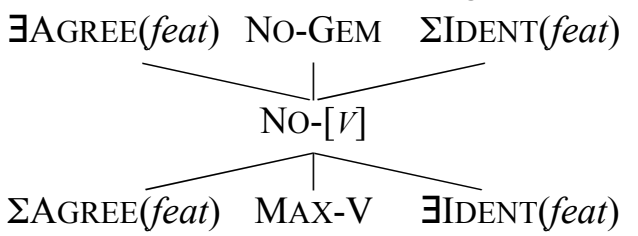

McCarthy (1986:241-242) cites Syrian Arabic (Cowell 1964) as having this pattern, but Odden (1988:466-467) notes problems with McCarthy's account (Blevins (2003:508-509) sketches an alternative). A more promising example of this pattern is found in Hindi (Ohala 1977, 1983, Pandey 1990), where schwas delete in $\mathrm{VC}_{1} \_\mathrm{C}_{2} \mathrm{~V}$ contexts except under certain conditions, one of these being when $\mathrm{C}_{1}$ and $C_{2}$ are homorganic. Schwa deletion is variable and dependent on speech rate, but Pandey (1990:308) is clear that forms in which schwa deletion is blocked between homorganic consonants are "characteristic of normal tempo, as are [...] forms with [schwa deletion between heterorganic consonants]".

(31) Schwa deletion in Hindi ("normal tempo"): unless flanking Cs are sufficiently identical
a. $/ \mathrm{t}^{\mathrm{h}} \partial p \partial k+\mathrm{i}: / \rightarrow\left[\mathrm{t}^{\mathrm{h}} \partial p k \mathrm{i}:\right] \quad$ 'a pat'
b. /nəkəl+i:/ $\rightarrow$ [nəkli:] 'counterfeit'
c. /ka:nən $+\mathrm{i}: / \rightarrow$ [ka:nəni:] 'a garden'
d. /a:tata:y+i:/ $\rightarrow$ [a:tota:yi:] 'tyrranical'
e. $/ \mathrm{a}: d \partial t+\tilde{\mathrm{e}}: / \quad \rightarrow \quad[\mathrm{a}: d \partial t \tilde{\mathrm{e}}:]$ 'habits' 
At faster rates of speech, deletion applies more regularly in all forms - and when it applies between otherwise different homorganic stops, as in (32)c below, the second assimilates completely to the first. ${ }^{9}$

(32) Schwa deletion in Hindi ("allegro tempo"): even if flanking Cs are sufficiently identical
a. /ka:nən+i:/ $\rightarrow$ [ka:nni:] 'a garden'
b. /a:tataay + ii $/ \rightarrow$ [a:tta:yi:] 'tyrranical'

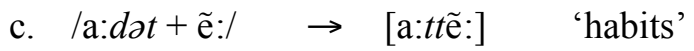

Ohala states that schwa deletion is specifically blocked by "the sequential constraint of Hindi which states that two stops of the same point of articulation do not follow each other" (Ohala 1977:171, emphasis added). Ohala (1983:56) exempts geminate stops from this constraint by "treating as long consonants stops with the same point of articulation that have similar voicing, e.g., $t t, p p$, etc." The fact that geminates are allowed but not derived via schwa deletion can be accounted for here as follows: NO-GEM is dominated and forced to be violated by constraints demanding faithfulness to input geminates, but it in turn dominates and forces violation of the constraint(s) responsible for schwa deletion.

I am taking the fact that there is voicing assimilation between the otherwise identical stops in (32)c in allegro tempo to be sufficient evidence that the blocking of deletion in (31)e in normal tempo is due to antigemination. This is unfortunately the only pair of examples of its kind discussed by Ohala (1977, 1983); Pandey (1990:308) also mentions the pair [bədətər] [bəttər] 'worse', which is of course identical to (31)e $\sim(32) \mathrm{c}$ in relevant respects. But it should be noted that Ohala (1983:118-119) does not transcribe any voicing assimilation between consonants that are otherwise not identical.

(33) Schwa deletion in Hindi: sufficiently different Cs don't assimilate in voicing?
a. $/ u g^{h} \partial t+\mathrm{a}: / \rightarrow$ [ug $\left.{ }^{h} \mathrm{ta}:\right] \quad$ 'disclosed'
b. $/ \mathrm{p}^{\mathrm{h}} \mathrm{d} d \partial k+\mathrm{i}: / \rightarrow$ [p $\left.\mathrm{p}^{\mathrm{h}} \mathrm{d} d \mathrm{ki}:\right] \quad$ 'a type of bird'
c. $/ \mathrm{d}^{\mathrm{h}} \partial d^{h} \partial k+\mathrm{a}: / \rightarrow\left[\mathrm{d}^{\mathrm{h}} \partial d^{h} k \mathrm{a}:\right] \quad$ 'fan a fire (imp.)'

One of Ohala's $(1977: 172,1983: 139-140)$ conditions on the application of schwa deletion that "[t]he output of the rule will not violate the sequential constraints of Hindi”, one of these constraints being that "[morpheme-]initially and finally, if $\mathrm{C}_{1}$ is either a stop or a fricative and $\mathrm{C}_{2}$ is either a stop or a fricative, they must agree in voicing" (Ohala 1983:57). Ohala (p.c.) clarifies that some of her proposed sequential constraints, perhaps including this one, are only meant to apply lexically. In more recent work, however, Ohala (2001:116-117) shows that there is assimilation of voicing in clusters similar to those in (33) across

\footnotetext{
${ }^{9}$ Based on the variant form in (32)a, Odden (1988:465) classifies Hindi schwa deletion as a case of 'delete a vowel blindly' (see §5.2.3). Thanks go to an anonymous reviewer for suggesting that I investigate the Hindi pattern more closely, and to Manjari Ohala for very timely and helpful responses to my questions about the relevant facts over e-mail. Incidentally, Ohala points out (p.c.) that the two examples in (32)a,b may not undergo deletion because they are loanwords (Ohala 1983:138-139).
} 
morpheme/word boundaries in unscripted (i.e., recorded but spontaneous) speech. Ohala (p.c.) suggests that this assimilation may apply in the examples in (33), or that "the first stop of the cluster may be rendered without complete voicing", but that these conjectures remain to be verified instrumentally.

\subsubsection{Delete a vowel unless flanking Cs are completely identical}

In order to describe this pattern, all AGREE(feat) constraints must be ranked below No- $[\mathrm{V}]$. This accounts for the fact that sequences of nonidentical adjacent consonants are tolerated and thus that deletion is allowed between them. Because NO-GEM is ranked above No- $[V]$, identical adjacent consonants are avoided by disallowing vowel deletion. All IDENT(feat) constraints must also be ranked above No-[ $\mathrm{V}]$ in order to rule out the possibility of vowel deletion and dissimilation between identical consonants (again, see $§ 5.4$ below). This ranking, shown in (34), entails that no features assimilate in the relevant set of contexts, and so there is again a necessary connection between the avoidance of only completely identical adjacent consonants, not merely sufficiently identical ones, and a lack of assimilation processes that might lead to such sequences.

(34) Delete a vowel unless flanking Cs are completely identical ((29)b)

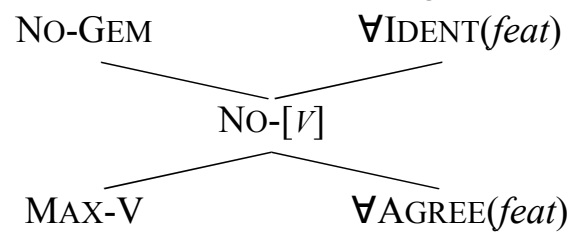

In Afar, an unstressed vowel is deleted in a peninitial two-sided open syllable unless the flanking consonants are identical.

(35) Deletion in Afar: unless flanking Cs are completely identical
a. /digib $+\mathrm{e} / \rightarrow$ [digbe]
'he married'
b. $/$ xamil $+\mathrm{i} / \quad \rightarrow \quad[\mathrm{xamli}]$ 'swamp grass'
c. $/$ danan $+\mathrm{e} / \rightarrow$ [danane] $/ *[$ danne $]$ 'he was hurt'
d. /midad $+\mathrm{i} / \quad \rightarrow \quad[$ midadi] $/ *[$ mid,di $] \quad$ 'fruit'

Bliese (1981:215) writes: "Since the language accepts geminates, it is not obvious why they are avoided here." Rose's solution, which I adopt here, is in relevant respects just like the one proposed for Hindi in $§ 5.2 .1$ above. First, No-GEM is not undominated; constraints that could be violated in order to get rid of underlying tautomorphemic geminates (e.g., MAX- $\mu$ ) must be ranked higher than NO-GEM for such geminates to be allowed to surface. Second, NO-GEM must be domain-sensitive in Afar, penalizing geminates only within a stem (or tautomorphemically) - the result being that only geminates derived by syncope are actually disallowed, because MAX- $\mu \gg$ NO-GEM $\gg$ NO- $[V]$. 
There are several consonantal assimilations in Afar (Bliese 1981:233ff), a few of which explicitly create geminates in apparent contradiction of the ranking in (34). Most of these processes apply solely between morphemes or words, and so the fact that they create geminates is not unexpected given the domain-sensitivity of No-GEM just noted. Two of the processes deserve comment, however. One is a process by which /h/ "assimilates to an adjacent fricative" (Bliese 1981:240). Bliese is careful to note about this particular process that "[a]lthough examples were only found at word boundary, word-internal counter examples were not found". None of the cited examples of syncope involve a flanking /h/ (or two flanking fricatives, for that matter); the bottom line, then, is that it is not possible to determine whether or not syncope would be blocked when the vowel is flanked by /h/ and another fricative.

The other process is described by Bliese (1981:239) as follows: "In the Wollo Aussa dialect, when word-internal $b$ follows $m$ they become a geminate $m$." Bliese adds that "[t]his occurs with the passive prefix $m$ ", but also cites comparative evidence suggesting that the process is not restricted to this morpheme: "there is also root-internal $m m$, versus $m b$ in other dialects." This suggests that syncope should be blocked between $/ \mathrm{m} /$ and $[\mathrm{b}]$ in the Wollo Aussa dialect, but Bliese explicitly notes that [mb] arises in this dialect from syncope (and place assimilation of nasals to following obstruents) between $/ \mathrm{n} / \mathrm{and} / \mathrm{b} /$. Assuming the $/ \mathrm{mb} / \rightarrow[\mathrm{mm}]$ process is indeed unrestricted, we appear to be confronted with a counterfeeding chain-shift; in serial terms, $/ \mathrm{mb} / \rightarrow[\mathrm{mm}]$ precedes either syncope or nasal place assimilation in the $/ \mathrm{nVb} / \rightarrow[\mathrm{mb}]$ mapping. This kind of process interaction attention to details of analysis discussion of which would take us well beyond the scope of this article (see e.g. Kirchner (1996), Lubowicz (2003)).

\subsubsection{Delete a vowel blindly}

In order to describe this pattern, NO-GEM must be ranked below NO- $[V]$; remaining rankings depend on whether or not any assimilation is expected to apply to the result of vowel deletion. For those features $\exists$ feat that are expected to assimilate even between otherwise identical consonants, $\exists \operatorname{AgREE}(f e a t)$ and No$[V]$ must be ranked above $\exists \operatorname{IDENT}(f e a t)$ and No-GEM; for those features $\Sigma$ feat that are not expected to assimilate, $\Sigma$ IDENT(feat) and No- $[V]$ must be ranked above both NO-[ $V]$ and $\Sigma$ AGREE(feat).

(36) Delete a vowel blindly $((29) \mathrm{c})$

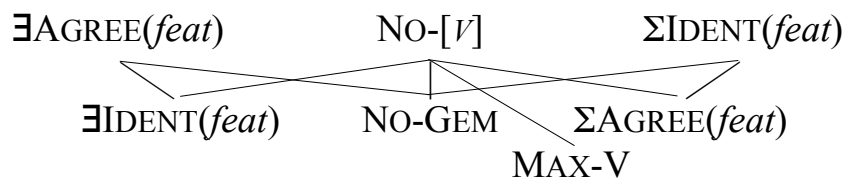

An example of this pattern comes from Klamath (Barker 1963, 1964). Klamath has a set of processes affecting nasal/lateral + lateral sequences (White 1973:34ff, Halle \& Clements 1983:113), some of which 
arise via vowel deletion, as shown in (37). One of these processes assimilates a nasal to a following (plain) lateral; the resulting geminate lateral in (37)d does not block the application of vowel deletion. (See Blevins (1993:268ff) on other processes affecting sequences of laterals differing in laryngeal features, and Barker (1964:67ff) on the behavior and distribution of the morphophonemes $\left\|^{\mathrm{V}}\right\|$ and $\left\|^{\mathrm{e}}\right\|$.)

(37) Blind deletion in Klamath
a. $/ \mathrm{CV}+l^{v}+o_{0} \mathrm{l} / \mathrm{H} \quad \rightarrow \quad[\mathrm{lo} l h \mathrm{i}]$
[nelhi]
'dist. put a round obj. inside'
b. $/ \mathrm{CV}+n^{e}+o_{o} \mathrm{y} /$
$\rightarrow$
[sal?a:l'a]
'dist. put a flat obj. inside'
c. $/ \mathrm{sV}+n^{e}+a l ' \mathrm{a}: 1^{\prime}+\mathrm{a} / \rightarrow$
[sallamna] 'puts a flat obj. into one's own fire'
d. $/ \mathrm{sV}+n^{e}+$ alamn $+\mathrm{a} / \rightarrow$ 'puts a flat obj. behind one's own back' 10

In his own presentation of Klamath as a case of blind deletion, Odden (1988:465) cites a different set of examples with obstruent clusters arising from vowel deletion. These obstruents differ only "in laryngeal features [which] should not influence the identity calculations performed by the OCP/Antigemination constraint, since laryngeal features are separate from supralaryngeal features". But as Barker (1964:21ff) and Blevins (1993:245ff) make clear, laryngeal features on Klamath obstruents contrast only before vowels and plain sonorants - positions of articulatory release (Kingston 1990, Lombardi 1995). Thus, in examples like [nekk'a] 'burns through (intr.)' (from $/ n V+k e k$ ' $+\mathrm{a} /$ ) and [č'liččc'a] 'strip tules with nails' (from $/ \check{c}^{\prime} l \mathrm{lV}+\check{c} i \check{c}{ }^{\prime}+\mathrm{a} /$ ), the relevant sequences are geminates with glottalization in the release, not adjacent similar-but-not-identical consonants. Compare also [hosqqa] 'puts on a dress (caus.)' from $/ \mathrm{hVs}+$ $q o q+\mathrm{a} /$ and [snocc'e:y'a] 'melts (caus.)' from /snV + c'oc'e:y' + a/ (Blevins 2003:506).

\subsubsection{Delete a vowel only if flanking Cs are completely identical}

In order to describe this pattern, NO-GEM must be ranked below No- $[V]$, which must in turn be ranked below all AGREE(feat) and IDENT(feat) constraints. This ensures that vowel deletion applies only between identical consonants; it is blocked if the flanking consonants disagree in terms of any features. Note that there may or may not be assimilation between otherwise adjacent consonants due to the undetermined ranking between $\forall \operatorname{AGREE}(f e a t)$ and $\forall \operatorname{IDENT}(f e a t)$, but deletion cannot feed complete assimilation between nonidentical consonants in order to satisfy the identity condition because both $\forall$ AGREE(feat) and $\forall \operatorname{IDENT}($ feat $)$ dominate NO-[V].

\footnotetext{
${ }^{10}$ Blevins (2003:506) cites the 'base' of (37)d as lalamna; this difference is irrelevant to the point made in the text.
} 
(38) Delete a vowel only if flanking Cs are completely identical ((29)d)

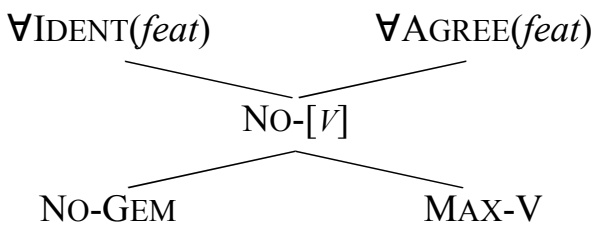

This pattern is found in Maliseet-Passamaquoddy (Sherwood 1986, LeSourd 1993, Odden 1988:464). Sherwood (1986:32) describes the situation as follows: "In a sequence of syllables each containing the short vowels /a/ or /ə/, vowels in odd-numbered syllables are weak and subject to syncope." (On the interaction between syncope and metrical structure in Passamaquoddy, see LeSourd (1993) and Hagstrom (1997).) Weak vowels syncopate in several contexts; most relevant here is that they "syncopate between identical consonants" (Sherwood 1986:33).

(39) Deletion in Maliseet-Passamaquoddy: only if flanking Cs are completely identical
a. $/$ te $p+\breve{a p} \mathrm{i}+\mathrm{w} /$
$\rightarrow$ [teppo]
'he sits inside'
b. $/ \mathrm{w}+\mathrm{t} \partial m+\partial m+\mathrm{a}+\mathrm{w}+\breve{\mathrm{a}} \mathrm{l} / \rightarrow$ [t'əmmal $]$ 'he bites him (obv.) in half'
c. /nəkwət $+\breve{a p} \mathrm{i}+\mathrm{w} /$
$\rightarrow\left[\mathrm{k}^{\mathrm{w}}\right.$ ’ətวpo $] / *\left[\mathrm{k}^{\mathrm{w}}\right.$ ’ətpo $]$
'he sits alone'
d. $/ \mathrm{w}+\partial l+\partial m+\mathrm{a}+\mathrm{w}+\breve{a} \mathrm{l} / / \rightarrow\left[\mathrm{t}^{\prime} \partial l \partial m \mathrm{al}\right] / *\left[\mathrm{t}^{\prime} \partial l m \mathrm{al}\right]$
'he bites him (obv.)'

\subsubsection{Delete a vowel only ifflanking Cs are sufficiently identical}

In order to describe this final pattern, a ranking very similar to that just discussed is necessary: NO-GEM must again be ranked below No-[ $V]$ and many (though crucially not all) AGREE(feat) and IDENT(feat) constraints. Because complete identity is not necessary for deletion to apply, either the AGREE(feat) constraints or the IDENT(feat) constraints referring to the feature(s) ignored in the determination of sufficient identity must be ranked with No-GEM below No- $[\mathrm{V}]$. The two possible rankings are shown in (40).

(40) Delete a vowel only if flanking Cs are sufficiently identical ((29)d)

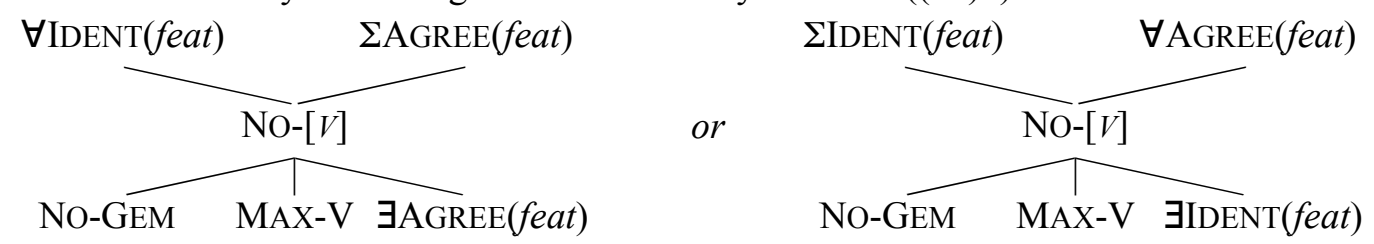

In the ranking on the left, deletion applies between sufficiently identical adjacent consonants because No- $[V]$ dominates $\exists \operatorname{AgREE}(f e a t)$ constraint. Note that this means that there is also no assimilation in terms of $\exists$ feat, because the corresponding IDENT(feat) constraints are undominated. ${ }^{11}$ In the ranking on the

\footnotetext{
${ }^{11}$ The exact same caveats about the precise ranking of $\exists \operatorname{IDENT}(f e a t)$ made in footnote 8 apply to the ranking on the left in (40).
} 
right, on the other hand, deletion between sufficiently identical consonants happens because assimilation can also apply — creating geminates — due to the subranking $\exists \operatorname{AGREE}(f e a t) \gg$ No- $[\mathrm{V}] \gg \operatorname{IIDENT}($ feat $)$.

The situation is thus identical, mutatis mutandis, to the one discussed in $\S 5.1 .5$ above: blocking of deletion only by sufficiently identical adjacent consonants (antigemination) depends on assimilation, while triggering of deletion only by sufficiently identical adjacent consonants (antiantigemination) is expected regardless of whether or not the features ignored in the determination of identity assimilate. In this case, examples of both of the predicted types of antigemination patterns exist. In Koya (Tyler 1969:38), "a vowel at the end of the word is deleted if the flanking consonants are identical (ignoring retroflexion)" (Odden 1988:463). $\exists$ feat is thus the set of features that distinguish retroflex coronals. Consistent with the ranking on the left in (40), retroflexion does not assimilate in the context of vowel deletion.

(41) Deletion in Koya: only if flanking Cs differ at most in retroflexion, no assimilation
a. /na: + ki \#ka: + va:li/ $\quad \rightarrow \quad$ [na:kka:va:li]
'to me it is necessary'
b. /a:ru \# ru:pa:y + ku/ $\rightarrow$ [a:rru:pa:yku]
'six rupees'
c. /pa:ta \#to:pi/ $\rightarrow$ [pa:tto:pi]
'old hat'
d. /verka:di $i$ digg $+\mathrm{t}+\mathrm{e} / \quad \rightarrow \quad$ [verka:ddigte]
'the cat got down'

A pattern of syncope in Telugu (Krishnamurti 1957:180ff) corresponds to the ranking on the right in (40). Odden (1988:463) writes that "a short vowel deletes if the flanking consonants are homorganic (in coronals, minor features such as [distributed] are ignored, and along with voicing are subject to regressive assimilation)". $\exists$ feat is thus the set of minor place features and voicing, both of which assimilate in the context of vowel deletion.

(42) Deletion in Telugu: only if flanking Cs differ at most in minor place and voicing, assimilation
a. /cu:ci \# ceppu/
$\rightarrow \quad[\mathrm{cu}: c c \mathrm{ppu}]$
'look in and tell'
b. /pa:ta \# talupu/
$\rightarrow \quad$ [pa:ttalupu]
'old door'
c. /pa:ta \# ceppu/
$\rightarrow \quad$ [pa:cceppu]
'old sandal'
d. /tarugu + ga: \# wundi/
$\rightarrow \quad$ [tarugga:wundi]
'it is deficient'
e. /peruku+ko:/
$\rightarrow \quad[$ perukko:]
f. /ceruku \# gada/
$\rightarrow \quad$ [ceruggada]
'pull it out for yourself'
'sugarcane stick'

The Telugu pattern has an added twist. Manner features such as nasality are also ignored, but do not assimilate: /gula:bi \# mogga/ $\rightarrow$ [gula:bmogga] 'rose bud'. This indicates that the $\exists$ AGREE(feat) and ᄏIDENT(feat) constraints referring to these ignored manner features are positioned as in the ranking on the left in (40) while those referring to minor place and voicing are positioned as in the ranking on the right. 


\subsection{Interim summary and remarks}

The revised and expanded versions of Odden's typology of relevant vowel insertion patterns (18) and vowel deletion patterns (29) have thus far been accounted for. Of particular interest is the distinction predicted between antigemination patterns, in which ignored features must assimilate $(\S 5.1 .1, \S 5.2 .1)$, and antiantigemination patterns, in which ignored features may or may not assimilate $(\S 5.1 .5, \S 5.2 .5)$. This distinction arises due to the different motivations behind antigemination and antiantigemination under the present proposal, as noted at the end of §5.1.5: antigemination is due to the dominance of NO-GEM and the fact that assimilation between sufficiently identical adjacent consonants would lead to its violation, while antiantigemination is in large part due to the low-ranking and violation of NO-GEM.

This factorial typological result is also significant given the recent and independent criticisms by Blevins (2003, 2004) and Reiss (2003) of OCP-type constraint-based accounts of antigemination. Both of these authors cite Odden (1988) as having effectively demonstrated the untenability of McCarthy's (1986) claim that the OCP is a universal constraint on phonological representations and derivations, and put forth arguments against Rose's (2000) OT account in which NO-GEM and the OCP are universal but ranked and violable constraints.

Blevins's sole argument (2003:518-519) is an empirical one against Rose's (2000:101) assumption that "any output sequence of two identical consonants [...] constitutes a geminate, a single consonant with long duration." Blevins points to examples of languages in which "sequences of identical consonants can be rearticulated, but underlying geminates cannot." Whether or not this is a "serious empirical problem" is rendered irrelevant under the present proposal. Rose's representational assumption was made to properly distinguish NO-GEM from the OCP, as noted at the outset of $\S 5$; adjacent identical consonants violate NO-GEM, which is responsible for antigemination, while identical consonants separated by a vowel violate the OCP, which is responsible for antiantigemination. But the OCP is not necessary in the present proposal; antiantigemination is due not to specific triggering of syncope between sufficiently identical consonants by the OCP, but to specific blocking of syncope between sufficiently different consonants by AGREe(feat) constraints. No-GEM can thus be assumed, as clarified at the end of $\S 1$ above, to not distinguish between 'true' geminates and sequences of adjacent identical consonants. Whether or not other constraints distinguish these is presumably the empirical question that Blevins is concerned with, but one that does not impinge on anything of interest in the context of the present article.

Reiss (2003:331-333) also questions Rose's assumption that adjacent identical consonants violate NO-GEM but not the OCP, and remarks that "[s]ince she is working in an OT framework, Rose could, in principle, take these sequences to violate the OCP." While I agree with the general sentiment that con- 
straint formulation in OT should take full advantage of ranking and violability, the claim that the OCP is violated by these sequences is empirically distinguishable from Rose's claim that it is not, and in fact would not allow Rose's account of antiantigemination to work: if the OCP were violated by adjacent identical consonants, there would be no way to compel syncope only between identical consonants.

The remainder of Reiss's critique of Rose (2000) concerns the analysis of antigemination patterns that ignore specific features; I of course agree that this is precisely the empirical arena in which all accounts prior to the present one (including the one in Reiss (2003); see $\S 6$ below) have failed to provide principled analyses. But I have only addressed Odden's typology so far, which is only a part of the broader factorial typology predicted by the free interaction among NO-GEM, AGREE(feat) and IDENT(feat) constraints. In the next two subsections I discuss the remainder of the predicted factorial typology. This discussion will be substantially less detailed than that of Odden's typology, primarily for reasons of space.

\subsection{Triggering of dissimilation (and blocking of assimilation)}

The risk of NO-GEM violation can in principle result in triggering of an otherwise unexpected dissimilation process. This results from those rankings in which NO-GEM and DEP-V/NO- $[V]$ are crucially ranked above both $\exists \operatorname{AGREE}(f e a t)$ and $\exists \operatorname{IDENT}(f e a t)$. (I collapse here the distinction between vowel insertion and vowel deletion between flanking consonants, which are primarily regulated by DEP-V and NO-[V], respectively, by making reference to 'DEP-V/NO-[V]'.) This is schematized in (43) below.

(43) Minimal ranking necessary to compel dissimilation of $\exists$ feat

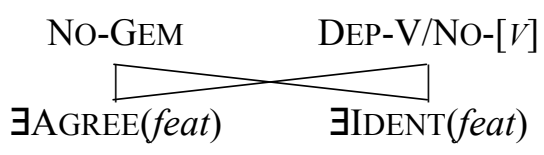

If $\exists \operatorname{AGREE}(f e a t)$ also dominates $\exists \operatorname{IDENT}(f e a t)$, then assimilation of $\exists$ feat is expected between consonants that differ in terms of at least one feature not in the $\exists$ feat set - in other words, there is both triggering of dissimilation and blocking of assimilation for $\exists$ feat when adjacent consonants are otherwise identical. If $\exists \operatorname{IDENT}($ feat) dominates $\exists \operatorname{AGREE}($ feat $)$, on the other hand, there is only dissimilation since there is no independent assimilation process to block. Whether or not any of the remaining features $\Sigma$ feat independently undergo assimilation or trigger epenthesis / block deletion depends on the relative ranking of $\Sigma \operatorname{AgREE}(f e a t), \Sigma \operatorname{IDENT}(f e a t)$, and DEP-V/No-[V]: $\Sigma$ AGREE(feat) and DEP-V/No-[V] ranked above $\Sigma \operatorname{IDENT}(f e a t)$ entails assimilation, while $\Sigma$ AGREE(feat) and $\Sigma$ IDENT(feat) ranked above DEP-V/No-[ $V]$ entails triggering of epenthesis / blocking of deletion.

Since the options for $\Sigma f e a t$ are in principle completely independent of those for $\exists$ feat, this part of the factorial typology results in six basic patterns. (This is of course a significant oversimplification since the 
behavior of every feature is in principle independent of the behavior of every other feature.) These six basic patterns are summarized in (44) below.

(44) Basic patterns predicted, given dissimilation of $\exists$ feat (43)

\section{Expectations for $\exists$ feat}

a. Assimilation (blocked by NO-GEM)

b. Assimilation (blocked by NO-GEM)

c. Assimilation (blocked by NO-GEM)

d. No assimilation

e. No assimilation

f. No assimilation
Expectations for $\Sigma f e a t$

Assimilation

Triggering of epenthesis / blocking of deletion

Neither

Assimilation

Triggering of epenthesis / blocking of deletion

Neither

Further detailed empirical work is necessary in order to determine whether each of these predicted typological slots is in fact attested, but I briefly present here three potential examples, the first of the type of pattern in (44)a-c and the other two of the type of pattern in (44)d-f.

The first example is found in Spanish, where nasal consonants assimilate in place of articulation to following consonants, except before other nasals (Harris 1984a, b). ${ }^{12}$ Morpheme-internal $m n$ sequences

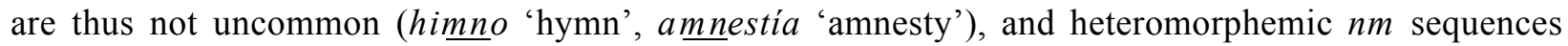
abound (inmoral 'immoral', conmemoración 'commemoration'). One way to interpret these apparent exceptions to nasal place assimilation is to say that the process is blocked by NO-GEM, because NO-GEM » AGREE(place) 》IDENT(place). The other prediction made by this ranking, however, is that NO-GEM should also trigger dissimilation of place (at least between nasals). This prediction appears to be only imperfectly borne out across different dialects of Spanish. Harris (1984b:155ff) cites "only one word in common use with a morpheme-internal [sequence of identical nasals]", perenne 'perennial', proposes to set this example "aside as an isolated exception", and notes in support of this that in "[c]ertain dialects", "the etymologically correct but uniquely exceptional standard form pere[nn]e has been replaced by pere $[\mathrm{mn}] \mathrm{e.}$

Harris also cites heteromorphemic innoble 'ignoble' and innecesario 'unnecessary', both of which are pronounced with geminate [nn]. The underlying form of the prefix in these examples has an alveolar nasal, as can be deduced from prevocalic examples such as inafectado 'unaffected' and inútil 'useless' (Harris 1984b:167); it could thus be said that the predicted dissimilation process is blocked by the markedness of the dissimilatory change from $/ \mathrm{n} /$ to $[\mathrm{m}]$ - something that can be achieved, for example, by a

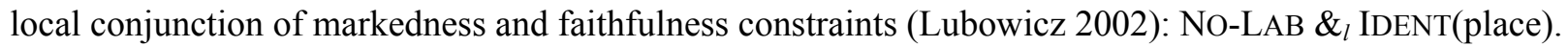

\footnotetext{
12 Thanks to Colin Wilson for help identifying this case.
} 
The second and third examples, where there is dissimilation but not assimilation of $\exists$ feat, involve cases in which only one half of a geminate consonant undergoes a process (what Keer (1999:89ff) calls 'geminate fission'). In Ponapean reduplication, geminate nonnasals are avoided via nasalization of the first half: $/$ pap + pap/ $\rightarrow$ [pampap] 'swim', /sas + sas/ $\rightarrow$ [sansas] 'stagger' (Rehg \& Sohl 1981). (Geminate nasals, on the other hand, are tolerated and even independently created: $/ \mathrm{mem}+m \mathrm{em} / \rightarrow$ [memmem] 'sweet', /nur + nur/ $\rightarrow$ [nunnur] 'contract'.) In Japanese, voiced geminate obstruents are disallowed; where a voiced stop is expected to geminate, it becomes a nasal + voiced stop cluster: [koga] 'brown' [koygari] '(intens.)'; cf. [huku] 'plump, puffy' [hukkuri] '(intens.)' (McCawley 1968).

The possibility that adjacent sufficiently identical consonants can be avoided by dissimilation is not unique to the present proposal and no alternative that I am aware of can disallow dissimilation in principle. The extent to which dissimilation may not be generally found as a strategy to avoid geminates or near-geminates thus appears to be an issue for phonological theory in general.

\subsection{Independence of NO-GEM and AGREE(feat)}

One consequence of the factorial typology under discussion in this section is that NO-GEM and $\exists \operatorname{AGREE}(f e a t)$ are each predicted to be capable of triggering epenthesis or blocking deletion independently of the other, the former to avoid adjacent identical consonants — or sufficiently identical ones, together with some other AGREE(feat) constraint(s) - and the latter to avoid $\exists$ feat-disagreement. In other words, epenthesis might be triggered under the disjunctive conditions and ranking in (45)a and deletion might be blocked under the disjunctive conditions and ranking in (45)b.

(45) Independent interaction patterns predicted

a. Insert a vowel if flanking Cs are (sufficiently) identical or they disagree in $\exists$ feat. ヨIDENT(feat) No-GEM $\exists$ AGREE(feat)

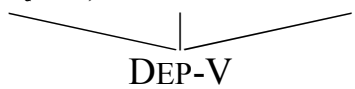

b. Delete a vowel unless flanking Cs are (sufficiently) identical or they disagree in $\exists$ feat.

ヨIDENT(feat) No-GEM $\exists$ AGREE(feat)

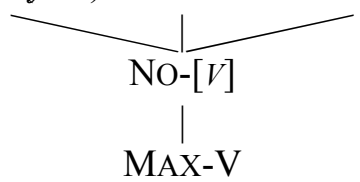

I have argued throughout this article that AGREE(feat) constraints can be optimally satisfied by segmental manipulations such as deletion and epenthesis, and several of the rankings already presented in this section crucially depend on this possibility. It is therefore interesting to note that there is a crucial distinction between the two patterns in (45) that is not specifically addressed in the 'too many solutions' 
literature cited in $\S 2$ : the discussion in this literature has focussed on whether or not AGREE(feat)-type constraints can trigger vowel epenthesis (or consonant deletion), but in (45)b, AGREE(feat) is responsible for blocking vowel deletion. Whether or not such patterns are attested remains to be seen.

\section{Summary and concluding remarks}

The content of the main proposal put forth in this article can be concisely summarized as follows: sufficiently identical antigemination is the combined result of geminate avoidance and the independent avoidance of adjacent consonants that differ in terms of the feature(s) ignored in the determination of identity. This proposal was applied to the analysis of English past tense suffix allomorphy in $\S 3$ and of Lithuanian verbal prefix allomorphy in $\S 4$. The fact that voicing is ignored in the determination of identity in English, and that voicing and palatalization are ignored in Lithuanian, was shown to be dependent on the fact that sufficiently different adjacent consonants independently assimilate in terms of those features. ${ }^{13}$

A fundamental claim made here is that cross-linguistic differences in "what constitutes 'identical' segments" (Odden 1988:461) are not arbitrarily defined, and that the set of features ignored in the determination of adjacent consonant identity depends crucially on other, independently-motivated aspects of the grammar of the language in question. More recently, Reiss (2003) concurs with Odden (1988) that these cross-linguistic differences are arbitrarily defined, and Reiss's specific proposal is that individual rules of a language can be subject to various types of arbitrary featural identity conditions. But as Reiss notes (2003:323ff), his formalism is capable of expressing such unattested conditions as "the COMPLETE NONIDENTITY CONDITION (two segments must have opposite feature values for all of a given subset of features) or the VARIABLE PARTIAL IDENTITY CONDITION (two segments must be identical with respect to one member of a given subset of features, but it does not matter which particular member it is)". Anticipating potential objections about overgeneration, Reiss suggests that "all attested patterns must be generatable by the UG-given phonological capacity, but not all generatable patterns will arise, due to the nature of sound change and language acquisition" (ibid.), but does not articulate this idea fully enough to understand its consequences; see now Blevins (2004) for elaboration of a variant of this point of view.

The proposal made here suggests an explanation for the unattestedness of the identity conditions identified by Reiss, an explanation in terms of the (formal) content of the universal constraint component CON generally assumed in OT. The hypothesis is that constraints against arbitrarily similar adjacent seg-

\footnotetext{
${ }^{13}$ This basic proposal has some wider applicability. In Baković (forthcoming) I analyze an example in which an independentlymotivated raising process is blocked just in case it would create a sequence of adjacent identical vocoids. Sufficiently identical adjacent segment avoidance thus needn't depend on assimilation per se, only on the potential for some independently-motivated process to create adjacent identical segments.
} 
ments do not exist in $\mathrm{CON}$; there are only constraints against completely identical adjacent segments like NO-GEM and their possible interactions with other independently-motivated constraints in particular grammars. Given the very nice fit demonstrated in $\S 5$ between the factorial typology resulting from this proposal and known parts of the attested typology of identity conditions, additional constraints against arbitrarily similar adjacent consonants appear to be unnecessary. Whether or not this hypothesis can ultimately be upheld in its strongest form is an empirical question, but I am encouraged by much recent work that likewise seeks principled definitions of similarity and identity between adjacent and nonadjacent consonants (Berkley 2000, Côté 2004, Frisch et al. 2004). To the extent that the current proposal and these independent research programs are successful, we will have achieved a more thorough understanding of what it means for two segments to be "basically the same".

\section{References}

Alpher, Barry. (1973). Son of ergative: The Yir Yoront language of Northeast Australia. PhD dissertation, Cornell University.

Alpher, Barry. (1991). Yir-Yoront lexicon: sketch and dictionary of an Australian language. Berlin: Mouton de Gruyter.

Ambrazas, Vytautas (ed.) (1997). Lithuanian grammar. Vilnius Baltos: Lankos.

Anderson, Stephen. (1973). Remarks on the phonology of English inflection. Language and Literature 4. 33-52.

Archangeli, Diana and Douglas Pulleyblank. (to appear). Harmony. In P. de Lacy (ed.) The Cambridge Handbook of Phonology. Cambridge: Cambridge University Press.

Baković, Eric, and Colin Wilson. (2004). Laryngeal markedness and the typology of repair. Paper presented at the 78th Annual Meeting of the Linguistic Society of America, Atlanta.

Baković, Eric. (2005). Partial identity avoidance as cooperative interaction. In Proceedings of WECOL 2004. Available as ROA-698 from the Rutgers Optimality Archive.

Baković, Eric. (forthcoming). Hiatus resolution and cooperative interaction. In S. Colina and F. MartinezGil (eds.) Optimality-theoretic Studies in Spanish Phonology. Amsterdam: John Benjamins.

Baković, Eric. (to appear). Local assimilation and constraint interaction. In P. de Lacy (ed.) The Cambridge Handbook of Phonology. Cambridge: Cambridge University Press.

Baković, Eric, and Cynthia Kilpatrick. (2005). Anteriority assimilation in English. Paper presented at the First International Conference on the Linguistics of Contemporary English, University of Edinburgh.

Barker, M. A. R. (1963). Klamath dictionary. Berkeley: University of California Press.

Barker, M. A. R. (1964). Klamath grammar. Berkeley: University of California Press.

Basbøll, Hans. (1972). Remarks on the regular plural formation of English nouns. Language and Literature 3. 39-42.

Beckman, Jill. (1998). Positional faithfulness. PhD dissertation, University of Massachusetts, Amherst. Published 1999, New York: Garland.

Benua, Laura. (1997). Transderivational identity: phonological relations between words. $\mathrm{PhD}$ dissertation, University of Massachusetts, Amherst. Published 2000, New York: Garland.

Benus, Stefan, Iris Smorodinsky, and Adamantios Gafos. (2004). Gestural coordination and the distribution of English 'geminates'. Penn Working Papers in Linguistics 10. 33-46.

Berkley, Deborah Milam. (2000). Gradient OCP effects. PhD dissertation, Northwestern University.

Blevins, Juliette. (1993). Klamath laryngeal phonology. IJAL 59. 237-279. 
Blevins, Juliette. (2003). Antigemination: natural or unnatural history? BLS 29. 499-522.

Blevins, Juliette. (2004). Evolutionary phonology: the emergence of sound patterns. Cambridge: Cambridge University Press.

Bliese, Loren F. (1981). A generative grammar of Afar. Arlington, TX: Summer Institute of Linguistics.

Bloch, Bernard. (1947). English verb inflection. $\operatorname{Lg}$ 23, 399-418.

Bolozky, Shmuel. (1972). Categorial limitations on rules in the phonology of Modern Hebrew. PhD dissertation, University of Illinois.

Bolozky, Shmuel. (1978). Some aspects of Modern Hebrew morphology. In R. Aronson Berman (ed.) Modern Hebrew structure. Tel-Aviv: University Publishing Projects, Ltd.

Bolozky, Shmuel. (1997). Israeli Hebrew phonology. In A. S. Kaye (ed.) Phonologies of Asia and Africa. Indiana: Eisenbrauns. 287-311.

Bolozky, Shmuel. (2004). Surface geminates in Israeli Hebrew. In L. H. Ehrlich et al. (eds.) Textures and meanings: thirty years of Judaic studies at the University of Massachusetts Amherst. Department of Judaic and Near Eastern Studies, University of Massachusetts, Amherst, http://www.umass.edu/judaic/anniversaryvolume/. 343-349.

Borowsky, Toni. (1986). Topics in the lexical phonology of English. PhD dissertation, University of Massachusetts, Amherst.

Borowsky, Toni. (1987). Antigemination in English phonology. LI 18. 671-678.

Côté, Marie-Hélène. (2004). Syntagmatic distinctness in consonant deletion. Phonology 21. 1-41.

Cowell, M. (1964). A reference grammar of Syrian Arabic. Washington, D.C.: Georgetown University Press.

Dambriunas, Leonardas, Antanas Klimas \& William Schmalstieg. (1966). Introduction to Modern Lithuanian. Brooklyn: Franciscan Fathers Press.

Davenport, Mike \& S.J. Hannahs. (1998). Introducing phonetics and phonology. London: Arnold.

de Lacy, Paul. 2002. The Formal Expression of Markedness. PhD dissertation, University of Massachusetts, Amherst. Available as ROA-542 from the Rutgers Optimality Archive.

de Lacy, Paul. (in press). Markedness in phonology: reduction and preservation. Cambridge: Cambridge University Press.

Frisch, Stefan A., Michael B. Broe \& Janet B. Pierrehumbert. (2004). Similarity avoidance and the OCP. NLLT 22. 179-228.

Fromkin, Victoria A. (ed.) (2000). Linguistics: an introduction to linguistic theory. Oxford: Blackwell.

Hagstrom, Paul. (1997). Contextual metrical invisibility. MIT Working Papers in Linguistics 30. 113-181.

Haiman, John. (1980). Hua: A Papuan language of the eastern highlands of New Guinea. Amsterdam: John Benjamins.

Halle, Morris \& George N. Clements. (1983). Problem book in phonology: a workbook for courses in introductory linguistics and modern phonology. Cambridge: MIT Press.

Harms, Robert. (1978). Some Nonrules of English. In M. A. Jazayery, E. C. Polomé \& W. Winter (eds.) Linguistic and literary studies in honor of Archibald A. Hill. Lisse: Mouton Publishers. 39-51.

Harris, James W. (1984a). Autosegmental phonology, lexical phonology, and Spanish nasals. In M. Aronoff \& R. Oehrle (eds.) Language Sound Structure. Cambridge: MIT Press. 67-82.

Harris, James W. (1984b). Theories of Phonological Representation and Nasal Consonants in Spanish. In P. Baldi (ed.) Papers from the XIIth Linguistic Symposium on Romance Languages. Amsterdam: John Benjamins. 153-168.

Hayes, Bruce. (1989). Compensatory lengthening in moraic phonology. LI 20. 253-306.

Hayes, Bruce, Bruce Tesar \& Kie Zuraw. (2003). OTSoft. Software package, http://www.linguistics.ucla.edu/people/hayes/otsoft/.

Hoard, J. E. \& C. Sloat. (1971). The inflectional morphology of English. Glossa 5. 47-56.

Hockett, Charles F. (1958). A course in modern linguistics. New York: Macmillan.

Keer, Edward. (1999). Geminates, the OCP, and the nature of CON. PhD dissertation, Rutgers Univer- 
sity. Available as ROA-350 from the Rutgers Optimality Archive.

Kenstowicz, Michael. (1972). Lithuanian phonology. Studies in the Linguistic Sciences 2. 1-85.

Kingston, John. (1990). Articulatory binding. In J. Kingston \& M. Beckman (eds.) Papers in Laboratory Phonology I. Cambridge: Cambridge University Press. 406-434.

Kiparsky, Paul. (1985). Some consequences of lexical phonology. Phonology 2. 85-138.

Kirchner, Robert. (1996). Synchronic chain shifts in Optimality Theory. LI 27. 341-350.

Krishnamurti, Bh. (1957). Sandhi in modern colloquial Telugu. Indian Linguistics 17. 178-188.

Langacker, Ronald W. (1968). Language and its Structure. New York: Harcourt, Brace \& World.

LeSourd, Philip. (1993). Accent and syllable structure in Passamaquoddy. New York: Garland.

Lombardi, Linda. (1991). Laryngeal features and laryngeal neutralization. $\mathrm{PhD}$ dissertation, University of Massachusetts, Amherst.

Lombardi, Linda. (1995). Laryngeal neutralization and syllable wellformedness. NLLT 13. 39-74.

Lombardi, Linda. (1996). Restrictions on direction of voicing assimilation: an OT account. University of Maryland Working Papers in Linguistics 4.

Lubowicz, Ania. (2002). Derived environment effects in Optimality Theory. Lingua 112. 243-280.

Lubowicz, Ania. (2003). Contrast preservation in phonological mappings. PhD dissertation, University of Massachusetts, Amherst.

Luelsdorff, Philip A. (1969). On the phonology of English inflection. Glossa 3. 39-48.

Lynch, John. (1978). A grammar of Lenakel. Canberra: Australian National University.

Mathiassen, Terje. (1996). A short grammar of Lithuanian. Columbus: Slavica.

McCarthy, John. (1986). OCP effects: gemination and antigemination. LI 17. 207-263.

McCarthy, John. (2004). Headed spans and autosegmental spreading. Ms, University of Massachusetts, Amherst. Available as ROA-685 from the Rutgers Optimality Archive.

McCawley, James D. (1968). The phonological component of a grammar of Japanese. The Hague: Mouton.

Mester, Armin \& Junko Ito. (1989). Feature predictability and underspecification: palatal prosody in Japanese mimetics. $\operatorname{Lg}$ 65. 258-293.

Odden, David. (1988). Antiantigemination and the OCP. LI 19. 451-475.

Odden, David. (2005). Introducing phonology. Cambridge: Cambridge University Press.

Ohala, Manjari. (1977). The treatment of phonological variation: an example from Hindi. Lingua 42. 161176.

Ohala, Manjari. (1983). Aspects of Hindi phonology. Delhi: Motilal Banarsidass.

Ohala, Manjari. (2001). Some patterns of unscripted speech in Hindi. Journal of the International Phonetic Association 31. 115-126.

Pandey, Pramod Kumar. (1990). Hindi schwa deletion. Lingua 82. 277-311.

Pater, Joe. (2003). Balantak metathesis and theories of possible repair in Optimality Theory. Ms, University of Massachusetts, Amherst.

Perlmutter, David. (1995). Phonological quantity and multiple association. In John A. Goldsmith (ed.) The Handbook of Phonological Theory. Oxford: Blackwell. 307-317.

Pinker, Steven \& Alan Prince. (1988). On language and connectionism: analysis of a parallel distributed processing model of language acquisition. In S. Pinker \& J. Mehler (eds.) Connections and symbols. Cambridge: MIT/Bradford Books. 73-193.

Prince, Alan \& Paul Smolensky. (1993/2004). Optimality Theory: Constraint interaction in generative grammar. Malden, MA and Oxford: Blackwell.

Pulleyblank, Douglas. (2002). Harmony drivers: no disagreement allowed. BLS 28. 249-267.

Rehg, Kenneth \& Damien Sohl. (1981). Ponapean reference grammar. Honolulu: University of Hawaii Press.

Reiss, Charles. (2003). Quantification in structural descriptions: attested and unattested patterns. The Linguistic Review 20. 305-338. 
Rose, Sharon. (2000). Rethinking geminates, long-distance geminates, and the OCP. LI 31. 85-122.

Selkirk, Elisabeth. (1991). A two-root theory of length. In E. Dunlap \& J. Padgett (eds.) University of Massachusetts Occasional Papers in Linguistics 14: Papers in Phonology. Amherst, MA: GLSA. 123-172.

Sherwood, David F. (1986). Maliseet-Passamaquoddy: verb morphology. Ottawa: National Museums of Canada.

Sneddon, J. N. (1975). Tondano phonology and grammar. Canberra: Australian National University.

Steriade, Donca. (1999). Phonetics in phonology: the case of laryngeal neutralization. In M. Gordon (ed.) Papers in Phonology 3 (UCLA Working Papers in Linguistics 2). 25-145.

Steriade, Donca. (2001a). The phonology of perceptibility effects: the P-map and its consequences for constraint organization. Ms, MIT, Cambridge, MA.

Steriade, Donca. (2001b). Directional asymmetries in place assimilation: a perceptual account. In E. Hume \& K. Johnson (eds.) The role of speech perception in phonology. San Diego: Academic Press. 219-250.

Tyler, S. (1969). Koya: an outline grammar, Gommu dialect. Berkeley and Los Angeles: University of California Press.

White, Robin B. (1973). Klamath phonology. Seattle: University of Washington.

Wilson, Colin. (2003). Analyzing unbounded spreading with constraints: marks, targets, and derivations. Ms, University of California, Los Angeles.

Yip, Moira. (1988). The obligatory contour principle and phonological rules: a loss of identity. LI 19. 65100. 